\title{
NUEVOS TAXONES DE LAPAROCERUS SCHOENHERR, 1834 DE EL HIERRO Y LA GOMERA, ISLAS CANARIAS (COLEOPTERA, CURCULIONIDAE, ENTIMINAE)
}

\begin{abstract}
A. Machado*
\section{RESUMEN}

A. Machado. 2011. Nuevos taxones de Laparocerus Schoenherr, 1834 de El Hierro y La Gomera, islas Canarias (Coleoptera, Curculionidae, Entiminae). Grael/sia, 67(1): 57-90.

Se describe el subgénero Fortunotrox n. subg. (especie tipo: Laparocerus gracilis Wollaston, 1865) del género Laparocerus Schoenherr, 1834, al que se atribuyen doce especies endémicas de las Canarias occidentales (El Hierro, La Palma y La Gomera). De la isla de La Gomera se redescribe L. indutus Wollaston, 1865. Los ejemplares que tradicionalmente se venían asignando a esta especie pertenecen en realidad a $L$. confusus $\mathbf{n}$. sp., que se describe junto con cuatro especies más: L. juelensis n. sp., L. rotundatus n. sp., L. pilosiventris n. sp., y L. magnificus n. sp. De la isla de El Hierro se describen: Laparocerus bimbache n. sp., L. cephalotes n. sp., L. orone hierrensis n. ssp., L. mateui tuberosus n. ssp., $L$. cavernarius $\mathbf{n}$. sp. y $\mathbf{L}$. hypogeus $\mathbf{n}$. $\mathbf{s p}$. De esta última isla se comentan cinco especies probablemente citadas por error, se cita por primera vez Laparocerus ellipticus Wollaston, 1863 y se aportan claves en español e inglés para determinar las especies de Laparocerus que la habitan.
\end{abstract}

Palabras clave: Taxonomía; nuevos taxones; islas Canarias; Macaronesia; Laparocerus; Fortunotrox; Curculionidae; Entiminae; El Hierro; La Gomera.

\section{ABSTRACT}

A. Machado. 2011. New taxa of Laparocerus Schoenherr, 1834 from El Hierro and La Gomera, Canary Islands (Coleoptera, Curculionidae, Entiminae). Graellsia, 67(1): 57-90 (in Spanish).

Subgenus Fortunotrox n. subg. (type species: Laparocerus gracilis Wollaston, 1865) of genus Laparocerus Schoenherr, 1834 is described and twelve species endemic of the Western Canaries (El Hierro, La Palma and La Gomera) are ascribed to it. Laparocerus indutus Wollaston, 1865 from the island of La Gomera is redescribed. Specimens traditionally assigned to this species belong to $L$. confusus $\mathbf{n}$. sp. that is described, as well as four more new species; L. juelensis n. sp., L. rotundatus n. sp., L. pilosiventris n. sp., and L. magnificus $\mathbf{n}$. sp. From the island of El Hierro the following taxa are described: $L$. bimbache $\mathbf{n}$. sp., L. cephalotes n. sp., L. orone hierrensis n. ssp., L. mateui tuberosus n. ssp., L. cavernarius n. sp. and L. hypogeus n. sp. From the latter island five species probably cited erroneously are discussed, Laparocerus ellipticus Wollaston, 1863 is recorded for the first time and keys in Spanish and English for identifying all Laparocerus inhabiting El Hierro are provided.

Keywords: Taxonomy; new taxa; Canary Islands; Macaronesia; Laparocerus; Fortunotrox; Entiminae; Curculionidae.

* c/ Chopin 1, 38208 La Laguna, Tenerife. e-mail: antonio.machado@telefonica.net 


\section{Introducción}

El género Laparocerus Schoenherr, 1834, con más de 150 especies, se distribuye en los archipiélagos de Madeira, Salvajes y Canarias, además de contar con una única especie en Marruecos occidental. En los últimos años el autor ha venido describiendo varios taxones nuevos procedentes de diferentes islas de la Macaronesia (Machado 2005, 2007a, 2007b, 2008a, 2008b). La presente contribución corresponde a la isla de El Hierro, aunque se incluyen también cinco especies nuevas de $\mathrm{La}$ Gomera que han surgido con posterioridad a la publicación del trabajo dedicado a dicha isla (Machado, 2007b) y a la aclaración de la identidad de Laparocerus indutus Wollaston, 1865, especie que se redescribe aquí.

Para facilitar el reconocimiento de los nuevos taxones, se aporta una clave que abarca todas las especies y subespecies conocidas de El Hierro, después de descartar algunas especies citadas aparentemente por error, y añadir una cita nueva. Al tratar las especies en la clave, se anotan sólo los subgéneros confirmados, incluido el subgénero Fortunotrox nov., endémico de las Canarias occidentales, que se describe en el presente trabajo. En relación a las nuevas especies descritas de La Gomera, se aportan las correcciones que hay que introducir en las claves publicadas en el trabajo arriba mencionado.

\section{Material y métodos}

El material objeto de estudio proviene de colecciones privadas o institucionales, y sobre todo, del recolectado por el autor durante varias campañas de prospección a lo largo de la pasada década. El total de ejemplares estudiados y referenciados en este trabajo supera el millar. Para las series típicas se ha escogido una sola localidad o localidades muy próximas, a fin de minimizar la variación genética. Los holotipos se han depositado en el Museo de Ciencias Naturales de Santa Cruz de Tenerife. Las siglas empleadas para referirse a las diferentes colecciones son las siguientes:

AAC Agustín Aguiar Clavijo, colección privada. La Laguna, España

AMC Antonio Machado Carrillo, colección privada. La Laguna, España.

DEI Deutsches Entomologisches Institut. Müncheberg, Alemania.

MNCN Museo Nacional de Ciencias Naturales. Madrid, España.
MNHN Muséum National d'Histoire Naturelle. París, Francia.

MZUR Museo di Zoología di la Universitá di Roma "La Sapienza". Roma, Italia.

NHM The Natural History Museum. Londres, Reino Unido.

NMW Naturhistorisches Museum Wien. Viena, Austria.

PS Peter Stüben, colección privada, Mönchengladbach, Alemania

RGB Rafael García Becerra, colección privada. S/C de La Palma, España.

TFMC Museo de Ciencias Naturales. Santa Cruz de Tenerife, España.

ULL Departamento de Zoología, Universidad de La Laguna, España

UMO University Museum, Hope Entomological Collections, Oxford, Reino Unido

Las disecciones fueron realizadas siguiendo los procedimientos entomológicos al uso. Las fotografías se tomaron con una cámara digital Nikon D70, con objetivo AF Micro Nikon $60 \mathrm{~mm}$ 1:28 D y anillo de extensión, usando luego el programa CombineZM de Alan Hadley para la fusión de toma secuencial. Los dibujos se realizaron con ayuda de una cámara clara montada sobre microscopio o lupa binocular, y para las mediciones se utilizó la lupa equipada con un micrómetro en el ocular. Las tallas se refieren a la longitud del insecto, descontado el rostro. Las letras L, A y H en la expresión de las ratio significan longitud, ancho y altura máximas, respectivamente. La terminología empleada es la que presenta el autor en su trabajo dedicado a la morfología de Laparocerus undatus Wollaston, 1864 (Machado 2010).

\section{Parte sistemática}

\section{Fortunotrox n. subgen.}

Especie tipo: Laparocerus gracilis Wollaston, 1865

Los estudios moleculares basados en el análisis de secuencias parciales de los genes mitocondriales de la citocromo oxidasa II y ribosomal 16S (pendientes de publicar) revelan la existencia de un grupo monofilético de Laparocerus restringido a las Canarias occidentales, constituido por tres subclados de especies. Se trata de Laparocerus de tamaño mediano a pequeño, cuerpo oblongo, con vestimenta de escamas formando dibujo y muchos de ellos con cerdas en los élitros más o menos desarrolladas. No hay caracteres morfológicos externos diferenciados que definan al conjunto, y sólo la conformación del edeago presenta un carácter diagnóstico aparentemente sólido. El saco interno es corto, y 
visto en posición de reposo resulta más corto que los temones o apenas los supera; el divertículo gonoporal es muy largo, tanto como el divertículo ciego, y se inserta ventral o ventrolateralmente por la izquierda.

Existen divertículos gonoporales igualmente muy alargados en especies del subgénero Amyntas, pero en éstas el saco rebasa muchísimo más la longitud de los temones y el divertículo se inserta casi a la altura en que terminan los temones.

El nombre escogido para este nuevo subgénero, Fortunotrox, deriva del nombre de "Afortunadas" con que se conocían en la Antigüedad a las islas Canarias (Insulae Fortunatae) y el término griego "trox" que significa escarabajo. Género gramatical masculino. Se asignan al subgénero las siguientes especies:

Grupo de L. gracilis

Laparocerus gracilis Wollaston, 1865

Laparocerus depressus Machado, 2007

Laparocerus spinimanus Machado, 2007

Laparocerus subopacus Wollaston, 1865

La Gomera

La Gomera

La Gomera

La Gomera

Grupo de L. orone

Laparocerus acutipennis Machado, 2007

Laparocerus benchijigua Machado, 2007

Laparocerus orone orone Machado, 2007

Laparocerus orone hierrensis nov. sp.

Laparocerus orone aridane Machado, 2009

La Gomera La Gomera

La Gomera

El Hierro

La Palma

Grupo de L. puncticollis

Laparocerus indutus Wollaston, 1865

Laparocerus confusus nov. sp.

Laparocerus juelensis nov. sp.

Laparocerus puncticollis Wollaston, 1864

Laparocerus decipiens Machado, 2009

Laparocerus indutus Wollaston, 1865

(Figs. 1A, 2A-C y F)

Laparocerus indutus Wollaston, 1865. Coleoptera Atlantidum: 325, Append: 53

Laparocerus (Laparocerus) tectus Marseul, 1872. Abeille, 11: 535 [nom. nov. innecesario]

Laparocerus indutus (= tectus Marseul), in Winkler, 1932. Cat. Coleopteror. Reg. Palaearct.: 1448 [syn.]

Laparocerus puncticollis indutus, in Roudier, 1957. Ann. Soc. Entomol. Fr., [1956], 125: 30

Laparocerus puncticollis indutus, in Lindberg \& Lindberg, 1958. Commentat. Biol., 17(1): 28

Laparocerus indutus, in Machado, 2006. J. Nat. Hist., 40(3537): 2022 [designación de lectotipo]

Laparocerus indutus, in Machado, 2009. Graellsia, 65(2): 218

Material examinado. Lectotipo. $10^{7}$ La Gomera, Messrs Crotch leg. (ex litt.) (NHM). Paralectotipo: $10^{7}$ mismos datos (MNHN, Coll. Oberthür-Wollaston).- Otro material: La Gomera, Tamargada, Lomo Palomos, 600 m (28R 280991
3120320), 16 exx 18-12-2010 leg. A. Machado, misma localidad y fecha 14 exx leg. P. Stüben (PS).

MedidAS DEL LECTOTIPO ( $\left(0^{x}\right)$. Longitud: total ( $\sin$ rostro) $4,6 \mathrm{~mm}$, rostro $0,50 \mathrm{~mm}$, escapo $1,00 \mathrm{~mm}$, funículo 0,94 (desmómeros I-IV respectivamente $0,26 / 0,18$ / 0,10 / 0,10 mm), maza $0,38 \mathrm{~mm}$, ojo 0,32 $\mathrm{mm}$, pronoto $1,10 \mathrm{~mm}$, élitros $3,35 \mathrm{~mm}$, tibias (pro/meso- /meta-) 1,08 /1,00 /1,14 mm. Anchura: cabeza (a nivel de los ojos) 0,96 mm, (interocular) 0,59 $\mathrm{mm}$; rostro (a nivel de los pterigios) $0,63 \mathrm{~mm}$, (mínimo dorsal) $0,48 \mathrm{~mm}$ (mínimo ventral) $0,63 \mathrm{~mm}$; escapo $0,12 \mathrm{~mm}$, maza $0,14 \mathrm{~mm}$, ojo $0,22 \mathrm{~mm}$, pronoto (anterior /máxima /posterior) $0,96 / 1,30 / 1,15 \mathrm{~mm}$ y élitros (máxima) 2,20 mm. Altura: abdomen 1,75 $\mathrm{mm}$.

REDESCRIPCIÓN. Machos: Longitud 3,5-4,7 mm. (media de 20 exx $=4,05 \mathrm{~mm}$ ). Laparocerus del subgénero Fortunotrox, de talla pequeña oblongo, moderadamente ancho. Tegumento brillante de color pardo negruzco salvo tarsos, tibias y antenas, generalmente más claros o rojizos; vestimenta de escamitas filiformes largas tumbadas y solapadas, de color dorado con visos verdes o cobrizos, alternando con zonas dominadas por escamitas hialinas, de modo que forman un dibujo parcheado en élitros y pronoto. Élitros provistos de setas recias erectas.

Antenas cortas, escapo algo más corto que la longitud del pronoto $(0,9 \mathrm{x})$, curvado al medio, gruesamente capitado en el cuarto apical; funículo corto, desmómero II igual o mayor que el I; maza oval, gruesa $(\mathrm{L} / \mathrm{A}=2,7)$.

Cabeza robusta, de base ancha (sienes divergentes); morro corto, trapezoidal; pterigios poco salientes, escroba anterior visible desde arriba; prorrostro sin puntear, con quilla epistomal completa, prolongada en breve carina mediana: metarrostro de lados convergentes hacia delante, sin acanalar, con línea media a su largo más o menos marcada; foseta frontal estrecha, prolongada hacia atrás. Ojos ovales $(\mathrm{L} / \mathrm{A}=1,45)$, poco prominentes (convexidad $25 \%$ o menos). Tegumento fuertemente punteado, con abundantes escamas.

Pronoto transversal (L/A $=0,85-0,9)$, de lados poco y uniformemente curvos; borde anterior y posterior algo convexos; área submarginal anterior a menudo algo deprimida. Tegumento con profusión de puntos mediocres y pequeños bien impresos, algo variables en separación (los mayores separados un diámetro entre sí o casi coalescentes). Sin setas, a lo sumo escamas erguidas en la zona antero-lateral. 

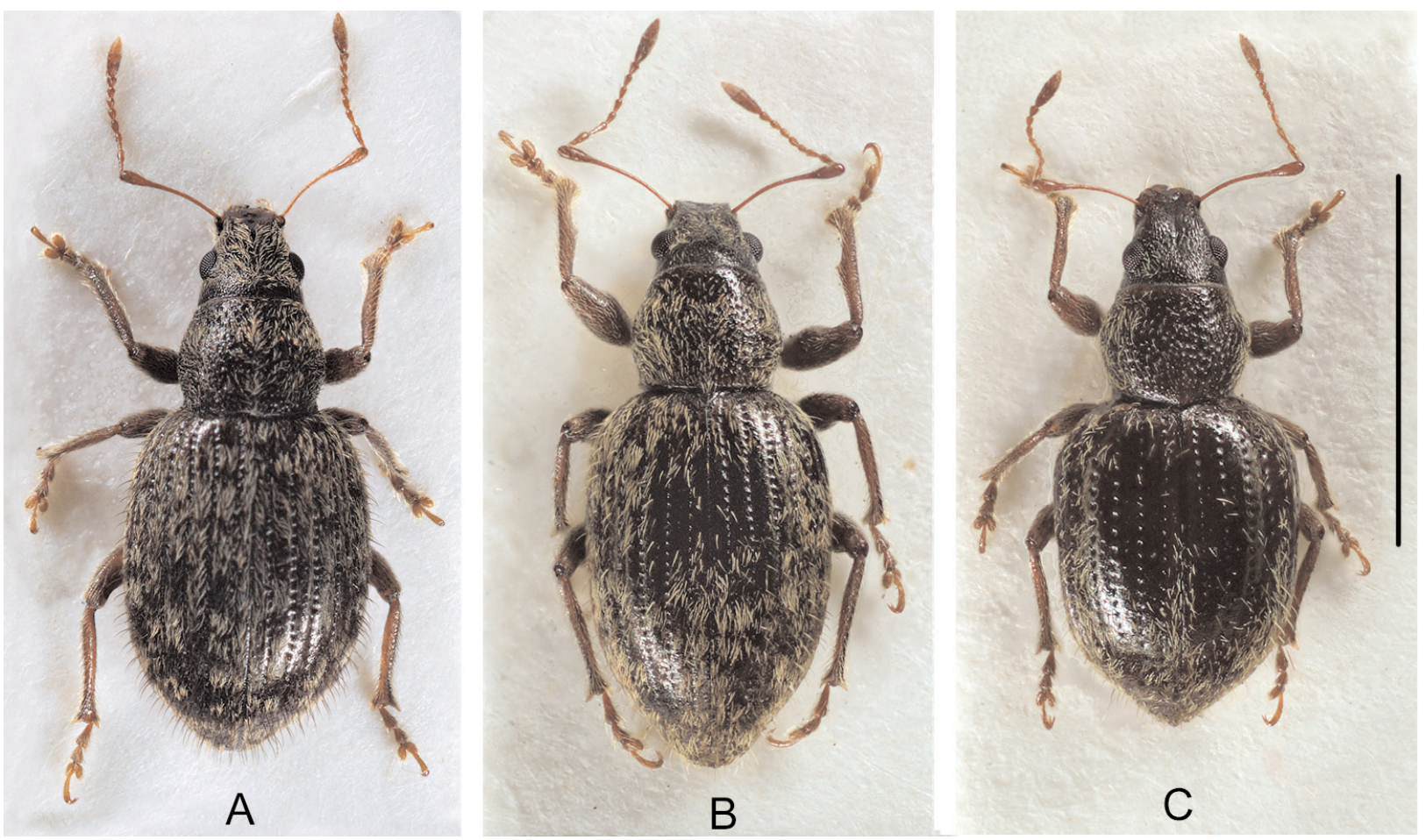

Fig 1.- Laparocerus indutus Wollaston, $1865 \sigma^{\pi}$ (A). Holotipo $\sigma^{\pi}$ de Laparocerus confusus n. sp. (B) y paratipo $ᄋ$

(C). Escala $=3 \mathrm{~mm}$.

Fig 1.- Laparocerus indutus Wollaston, $1865 \sigma^{\top 7}(\mathrm{~A})$. Holotype $\sigma^{\top}$ of Laparocerus confusus n. sp. (B) and paratype $\sigma^{7}(\mathrm{C})$. Scale $=3 \mathrm{~mm}$.

Escudete pequeño, liso, rara vez con escamitas.

Élitros subovales, anchos (1,6-1,7x pronoto), lados poco arqueados en los 2/3 anteriores, convergentes y algo acuminados hacia el ápice; hombros redondeados; estrías marcadas por puntos gruesos profundos (algo mayores que los del pronoto); interestrías subconvexas, de tegumento liso, con hileras simples de puntos setíferos y las setas erectas algo arqueadas y dirigidas hacia atrás, tanto o más largas que el doble del largo de una uña.

Patas cortas, tibias punteadas; protibias apicalmente ensanchadas a ambos lados y con mucrón en el ángulo anterior, escotadura interna de la mitad distal débil,el grosor al medio (sin dentículo o ángulo vivo) nunca el doble del grosor mínimo de la escotadura o inflexión. Mesotibias con mucrón; metatibias inermes y apenas más largas que las protibias.

Cara ventral punteada superficialmente, brillante, con pilosidad fina tumbada abierta. Quilla inter- mesocoxal apenas desarrollada. Ventritos rebordeados en su margen posterior; el último ligeramente truncado.

Edeago de punta estrecha y afilada, con el ápice romo; apertura ventral a partir de la mitad de lóbulo medio; el saco interno en reposo no rebasa los temones, con dos hileras de cuatro dientes muy grandes en su tramo medio (Figs. 2A-B).

Hembras: Longitud 3,5-4,3 mm. Muy parecidas al macho, salvo por los élitros más ovales $(\mathrm{L} / \mathrm{A}=$ $1,3)$ y el último ventrito más romo apicalmente. El pronoto igual que en los machos, a lo sumo con incipiente línea media, y sin ningún tipo de gibosidad en la base.

COMENTARIO. Laparocerus indutus fue descrita por Wollaston (1865) sobre tres ejemplares colectados por los hermanos Crotch en La Gomera, sin indicación de localidad. Posteriormente, Uyttenboogaart (1937) la incluye en unas claves sobre los Laparocerus de Canarias, aunque en su colección depositada en el 

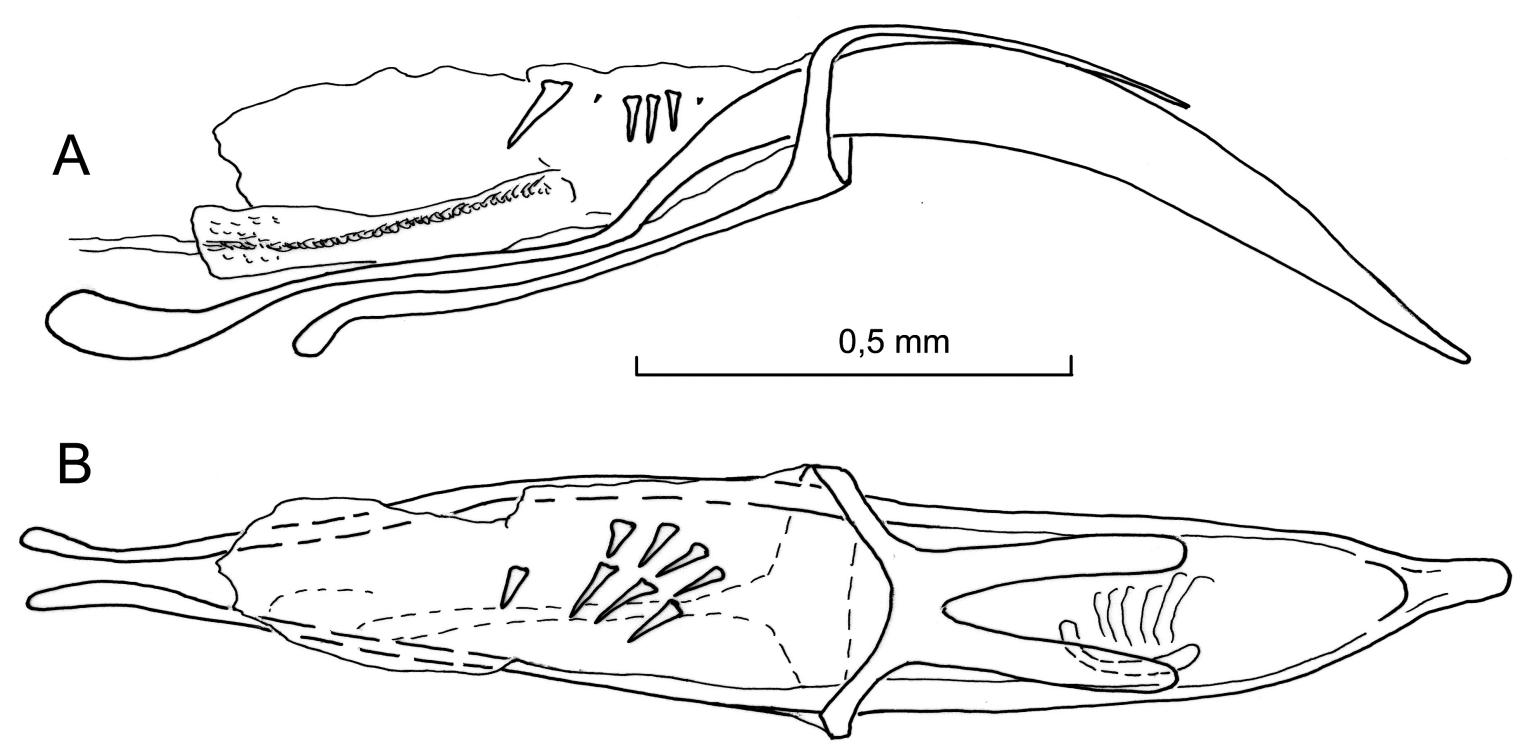
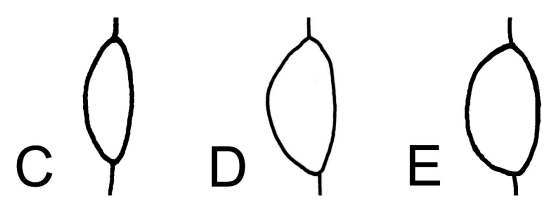

G

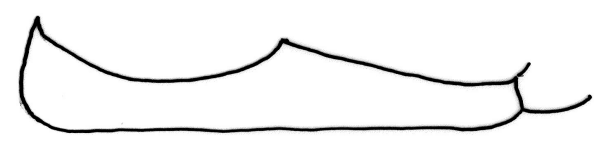

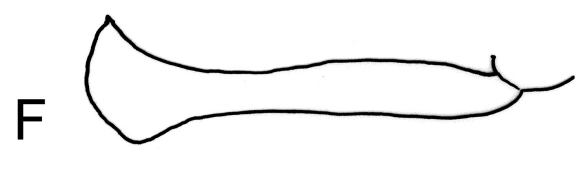

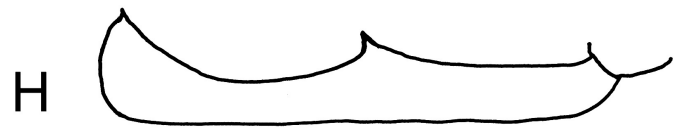

Fig. 2.- Edeago de Laparocerus indutus Wollaston, 1865. en vista lateral (A) y dorsal (B). Ojos de L. indutus (C), L. confusus n. sp. (D) y L. juelensis n. sp. (E). Protibias masculinas de L. indutus (F), L. confusus n. sp. (G) y L. juelensis n. sp. $(\mathrm{H})$.

Fig. 2.- Aedeagus of Laparocerus indutus Wollaston, 1865. in lateral view (A) and dorsal view (B). Eyes of $L$. indutus (C), L. confusus n. sp. (D) and L. juelensis n. sp. (E). Male protibiae of $L$. indutus (F), L. confusus n. sp. (G) and $L$. juelensis n. sp. $(\mathrm{H})$.

Museo de Historia Natural de Leiden no existen ejemplares de esta especie. Años después, Roudier (1956) la introduce en sus claves como subespecie de Laparocerus puncticollis Wollaston, 1864 de El Hierro, resaltando así el parentesco que ya señalara Wollaston. Según explican Lindberg \& Lindberg (1958: 58), el autor francés comparó el tipo de Wollaston depositado en Londres con un ejemplar de los 16 colectados por ellos en el Valle de Las Rosas. Con posterioridad, ningún otro autor se ha ocupado de la especie hasta que designé lectotipo al único ejemplar $\left(\sigma^{7}\right)$ existente en la Colección Wollaston en
Londres y paralectotipo a otro ejemplar masculino que fue a parar a la Colección Oberthür-Wollaston, conservada en París (Machado, 2006). Se desconoce el paradero del tercer ejemplar sintípico, pero posiblemente se trata también de un macho ya que Wollaston no menciona los caracteres de la hembra.

He venido determinando como L. indutus ejemplares de una especie bastante común en la isla (material propio, de instituciones y de varios colegas), cuyos machos encajan en la descripción de Wollaston y claves de Roudier, que tampoco menciona las hembras. El caso es que las hembras de 
esta especie contrastan mucho por presentar la base elitral llamativamente inflada (máxima anchura en el primer tercio) y un característico gránulo o quilla elevada en la base del pronoto. Sin embargo, una serie de Laparocerus recientemente capturada en Tamargada y cuyos machos también encajan en la descripción de L. indutus, presentan hembras con élitros ovales y carentes de gránulo o quilla pronotal. La duda sobre cual de las especies es el verdadero L. indutus ha quedado resuelta al comparar machos de ambas con el lectotipo. Éste y los machos de Tamargada son idénticos y tienen los ojos más pequeños y menos prominentes (Fig. 2C), el pronoto con lados más curvados y la escotadura interna de las protibias mucho menos desarrollada que en los otros machos. Las hembras de L. indutus son, pues las más sencillas y parecidas al macho.

A tenor de estos hallazgos se justifica la redescripción de $L$. indutus que antecede, describir la especie común y muy extendida con la que se venía confundiendo, y dar a conocer otra tercera, también de La Gomera, bastante localizada, que ha surgido a raíz de la revisión emprendida. Para incluir estas novedades en la clave de Laparocerus de La Gomera (Machado, 2007b, original en inglés) hay que modificarla del siguiente modo:

11 Size $>6 \mathrm{~mm}$; male protibia not or hardly emarginate

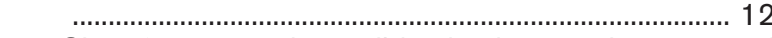

- $\quad$ Size $<6 \mathrm{~mm}$; male protibia clearly emarginate .... 11'

11' Emargination of male protibia deep and sharp, ending at mid-tibia in vivid angle or small spine. Maximum width of female elytra not at middle. Eyes prominent ..

- Emargination of male protibia shallow and smooth without spine or vivid angle. Maximum width of female elytra at middle (pronotum never elevated at base). Eyes less prominent ........ L. indutus Wollaston, 1865

11" Larger punctures of pronotum separated one diameter or less, small punctures deep and conspicuous. Female pronotum with a basal elevated granule or carina and elytra widest at basal third ................ $L$. confusus $\mathrm{n}$. sp.

- $\quad$ Larger punctures of pronotum smaller, separated more than two diameters, small punctures usually superficial. Female pronotum without basal granule or carina, and elytra widest behind middle L. juelensis n. sp.

DisTRIBUCIÓN Y ECOLOGíA. Laparocerus indutus es endémico de la isla de La Gomera y su presencia ha sido confirmada de momento en el valle de Tamargada, en la vertiente oriental de la isla, colectada sobre Erica arborea (Ericaceae) en hábitat abierto de sabinar (Juniperus turbinata canariensis, Cupressaceae).

\section{Laparocerus confusus $\mathrm{n} . \mathrm{sp}$.}

(Figs. 1B-C, 2D y G, y 3A-F)

= indutus auctt., non Wollaston, 1865

Material examinado. Holotipo. La Gomera, Laguna Grande (28R 027830311330$) 1250$ m, $10^{7} 18-4-2000$ leg. A. Machado (TFMC/CO-15951).— Paratipos: $270^{7} \sigma^{7}$ y 28 우 오, mismos datos (AMC,2 NHM); Cherelepín 1200 m, 20 $\sigma^{\top} \sigma^{\top}$ 14-9-2003 leg. A. Machado (AMC). Laguna Grande, 7 exx 6-12-2006 leg. R. García (RGB).- No paratipos: Abundante material de varias localidades: Teselinde, Chorros de Epina, Las Hayas, Jardín de las Creces, Los Barranquillos, Apartacaminos, Agua de Los Llanos, Raso de la Bruma, Pinar de Argumame, Cumbre de Juan Tomé, Pajarito (59 exx), Fuensanta, Piedra Encantada, Mora de Gaspar, El Cedro, Los Acebiños (106 exx), Juego de Bolas, La Zarcita, Enchereda, etc.

MedidAs DEL holotipo $\left(\sigma^{t}\right)$. Longitud: total ( $\mathrm{sin}$ rostro) $4,65 \mathrm{~mm}$, rostro $0,54 \mathrm{~mm}$, escapo $1,10 \mathrm{~mm}$, funículo 1,13 (desmómeros I-IV respectivamente $0,30 / 0,22$ / 0,15 / 0,14 mm), maza 0,44 mm, ojo $0,36 \mathrm{~mm}$, pronoto $1,10 \mathrm{~mm}$, élitros $3,20 \mathrm{~mm}$, tibias (pro- /meso- /meta-) 1,24 / 1,10/1,26 mm. Anchura: cabeza (a nivel de los ojos) 0,98 mm, (interocular) $0,58 \mathrm{~mm}$; rostro (a nivel de los pterigios) $0,61 \mathrm{~mm}$, (mínimo dorsal) $0,44 \mathrm{~mm}$ (mínimo ventral) 0,56 $\mathrm{mm}$; escapo $0,12 \mathrm{~mm}$, maza $0,13 \mathrm{~mm}$, ojo $0,26 \mathrm{~mm}$, pronoto (anterior /máxima /posterior) 0,98 / 1,30 / $1,10 \mathrm{~mm}$ y élitros (máxima) $2,15 \mathrm{~mm}$. Altura: abdomen $1,65 \mathrm{~mm}$.

DiagnOSIS. Longitud: $0^{\pi} \overbrace{}^{\pi} 4,1-5,3 \mathrm{~mm}$ y $ㅇ ㅜ$ 3,7-5,1 mm. El macho es muy parecido al de Laparocerus indutus Wollaston, 1865 y se distingue de él por presentar las antenas más largas, el morro más estrangulado dorsalmente, los ojos más prominentes (convexidad alrededor del $30 \%$ en vez del 20\%, ver figura 2D), los lados del pronoto más redondeados, los élitros menos ovalados, oblongos y ligeramente inflados en la base, el ángulo humeral más cerrado (hombros más marcados); la vestimenta de escamitas doradas más tumbadas y menos densa, las escamas hialinas piliformes menos abundantes y algo más cortas, las setas en los élitros menos abundantes (notorio en la región humeral), la escotadura de la cara interna de la protibia mucho más precisa (profunda y de borde cortante), terminando en ángulo vivo o pequeño diente (Fig. 2G). El saco interno del edeago presenta dos hileras de 6 a 8 dientes grandes (4+4 en indutus) acompañados de abundantes dientecillos entremezclados (Figs. 3C, D y F).

La hembra (Fig. 1C) es muy diferente del macho (y de la hembra de $L$. indutus), con el cuerpo corto y muy ancho $(\mathrm{L} / \mathrm{A}=1,3$ frente a 1,5 del macho); pre- 

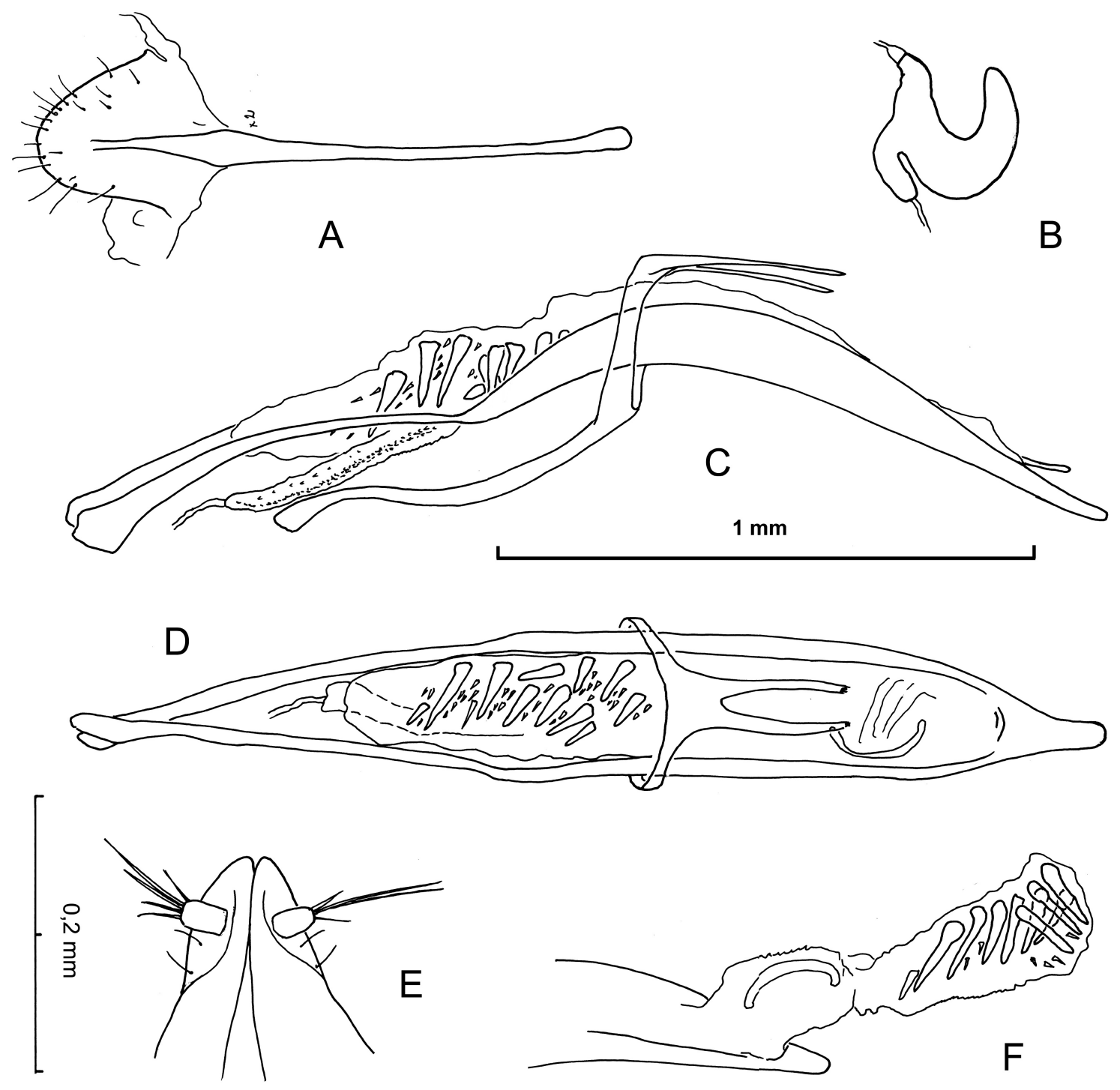

Fig. 3.- Laparocerus confusus n. sp. Urosternito VIII femenino (A), espermateca (B), edeago en vista lateral (C) y dorsal (D), gonostilo $(E)$ y detalle del saco interno del edeago evertido $(F)$.

Fig. 3.- Laparocerus confusus n. sp. Female urosternite VIII (A), spermatheca (B), aedeagus in lateral view (C) and dorsal view (D), gonostyli (E) and detail of everted internal sac of aedeagus (F).

senta un característico gránulo elevado al medio de la base del pronoto, que a menudo forma una breve quilla longitudinal; los élitros llamativamente inflados en la base, alcanzando la máxima anchura en el primer tercio; los lados convergen subparalelos hacia atrás para acuminarse más bruscamente en el tercio apical; los puntos de las estrías en la región humeral son muy superficiales, las setas suberectas están más separadas y las escamitas son aparentemente más dehiscentes que en el macho, y faltan con frecuencia. Las tibias son rectas, ampliamente abiertas en abanico en el ápice. Esternito VIII, espermateca y gonoestilos como en las figuras $3 \mathrm{~A}, \mathrm{~B}$ y E.

Etimología. El adjetivo latino confusus, confundido, hace alusión al equívoco que ha existido con esta especie, que se ha venido considerando como L. indutus Wollaston, 1865. 
COMENTARIO. Laparocerus confusus n. sp. pertenece al grupo de L. puncticollis Wollaston, 1864, que cuenta con un representante en El Hierro ( $L$. puncticollis), otro en La Palma ( $L$. decipiens Machado, 2009) y tres en La Gomera. Las diferencias con la especie palmera son las que atribuí en su diagnosis diferencial a $L$. indutus (non Wollaston), y de la especie herreña -más oblonga- se distingue y por el punteado de la cabeza y pronoto, que es muchísimo menos grueso y abigarrado, así como por la forma inflada de los élitros femeninos y el gránulo pronotal muchísimo más desarrollado. De las tres especies del grupo presentes en La Gomera, es la única cuyas hembras presentan gránulo o quilla en el pronoto, y los machos se distinguen bien de los de indutus, por los ojos más prominentes y lados del pronoto más curvados, y de los de $L$. juelensis $\mathrm{n}$. sp. por el punteado del pronoto, mucho más denso y marcado.

DisTRIBUCIÓN Y ECOLOGÍA. Laparocerus confusus n. sp. se distribuye por la zona central de la isla de La Gomera, a altitudes superiores a los $750 \mathrm{~m}$. Habita tanto el matorral montano como los claros y caminos del bosque, siendo común sobre Adenocarpus foliolosus (Fabaceae) y Rubus ulmifolius (Rosaceae), aunque es bastante polífago. También se ha colectado sobre Cistus monspeliensis (Cistaceae) Cedronella canariensis (Lamiaceae), Erica arborea (Ericaceae), Chamaecytisus proliferus (Fabaceae), Phyllis nobla (Rubiaceae), Sonchus sp. (Asteraceae), manzanos, helechos, etc.

\section{Laparocerus juelensis n. sp.}

(Figs. 4A y 5A-B)

Material eXaminado. Holotipo: La Gomera, Hermigua, Cruz de Juel (28R 02878073116452 ) 790 m, $10^{7}$ leg. A. Machado (TFMC/CO-15960).- Paratipos: misma localidad y fecha, 26 exx leg. A. Machado (AMC), 5 exx leg. R. García (RGB), 12 exx leg. A. Aguiar (AAC).

MedidAS DEL HOLOTIPO $\left(\sigma^{T}\right)$. Longitud: total ( $\sin$ rostro) $5,25 \mathrm{~mm}$, rostro $0,56 \mathrm{~mm}$, escapo $1,22 \mathrm{~mm}$, funículo 1,28 (desmómeros I-IV respectivamente 0,32 / 0,28 / 0,16/ 0,14 mm), maza 0,46 mm, ojo $0,32 \mathrm{~mm}$, pronoto $1,10 \mathrm{~mm}$, élitros $3,6 \mathrm{~mm}$, tibias (pro- /meso- /meta-) 1,34 /1,26/1,44 mm. Anchura: cabeza (a nivel de los ojos) 1,01 mm, (interocular) $0,58 \mathrm{~mm}$; rostro (a nivel de los pterigios) $0,66 \mathrm{~mm}$, (mínimo dorsal) $0,44 \mathrm{~mm}$ (mínimo ventral) 0,62 $\mathrm{mm}$; escapo $0,13 \mathrm{~mm}$, maza $0,14 \mathrm{~mm}$, ojo $0,26 \mathrm{~mm}$, pronoto (anterior /máxima /posterior) $1,07 / 1,40 /$
1,22 mm y élitros (máxima) 3,60 mm. Altura: abdomen $1,90 \mathrm{~mm}$.

Diagnosis. Longitud 3,9-5,7 $\mathrm{mm}\left(\sigma^{7} \sigma^{7}\right.$ media $4,8 ; \mathrm{n}=13)$ y 우 ᄋ media $4,6(\mathrm{n}=9)$. Especie muy parecida a $L$. confusus n. sp., pero de talla algo mayor, tegumentos más negruzcos y brillantes, con la cabeza menos robusta, morro de aspecto más estrecho, pronoto algo más transversal y élitros algo más alargados. El punteado del pronoto es notoriamente más abierto, con los puntos mayores más pequeños (bastante menores que los de las estrías elitrales) y separados 1,5-3 diámetros entre sí, y los menores más o menos superficiales sobre fondo brillante. Los élitros son más ovales, no tan subparalelos en el tramo medio (ancho élitro/ pronoto $=1,75$ frente a 1,53$)$, más alargados $(\mathrm{L} / \mathrm{A}=3,2$ frente a 2,9) y los hombros algo más uniformemente redondeados. La máxima anchura normalmente en la mitad posterior (nunca anterior); el campo de setas suberectas es igualmente poco denso, pero están menos desarrolladas, sobre todo en la mitad anterior, hacia la base. Las protibias masculinas son más robustas, con la escotadura muy pronunciada y mejor delimitada si cabe, terminando en un ángulo o diente mediano agudo y robusto, alcanzando la tibia en este punto una anchura $1,7 \mathrm{x}$ el grosor mínimo de la escotadura. Metatibias claramente más largas que las protibias. El edeago presenta el campo de dientes del saco interno mucho más desarrollado y extendido hacia delante y hacia atrás del punto de inserción del saco gonoporal, con dos hileras de 15 o más dientes grandes, además de los pequeños entremezclados (Figs. 5A-B).

El margen posterior del pronoto en las hembras es también algo convexo (saliente hacia atrás), pero la base es absolutamente normal, sin gibosidad o carena; los élitros son más anchos y abombados que en el macho, pero subovales, con la máxima anchura a los $2 / 3$ (nunca en la mitad anterior).

Se distingue fácilmente de $L$. indutus por presentar la talla mayor, tegumentos más negruzcos y brillantes, antenas más largas, ojos mucho más prominentes (Fig. 2E), práctica ausencia de escamitas piliformes hialinas en la cabeza y pronoto, élitros con máxima achura desplazada hacia atrás y las protibias masculinas con un fuerte diente mediano y escotadura preapical interna muy desarrollada y bien delimitada (Fig. 2H).

Etimología. El epíteto específico hace referencia al pago montañoso de Juel, en la isla de La Gomera, donde fue descubierta la especie. 

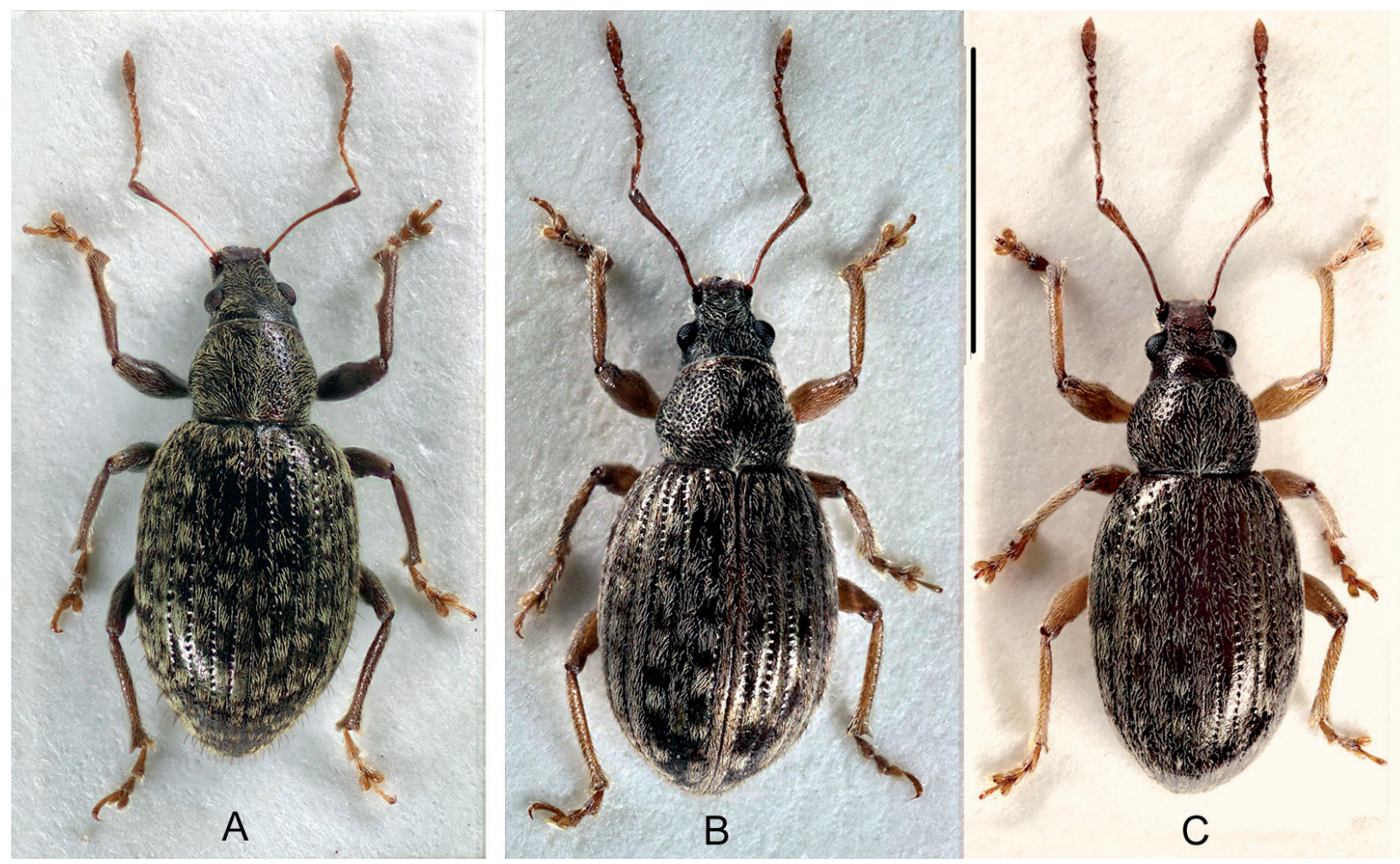

Fig. 4.- Holotipos $0^{7}$ de Laparocerus juelensis n. sp. (A), Laparocerus rotundatus n. sp. (B) y Laparocerus pilosiventris n. sp. (C).

Fig. 4.- Holotypes $\sigma^{7}$ of Laparocerus juelensis n. sp. (A), Laparocerus rotundatus n. sp. (B) and Laparocerus pilosiventris n. sp. (C).

DisTRIBUCIÓN Y ECOLOGÍA. La serie típica procede de la cresta de la Cruz de Juel, en el macizo de La Campana que flanquea el valle de Hermigua por el oriente. Fue colectada en el margen del bosque de laurisilva, sobre Cistus monspeliensis y otras plantas.

\section{Laparocerus rotundatus $\mathrm{n}$. $\mathbf{s p}$.}

(Figs. 4B y 6A-E)

Material eXAminado. Holotipo: La Gomera, infra Alajeró, $650 \mathrm{~m}$ (UTM 28R 02805603104954$) 10^{7} \mathrm{leg}$. A. Machado (TFMC/CO-15951)._- Paratipos: misma localidad y fecha, 24 exx leg. A. Machado (AMC), 14 exx leg. P. Stüben (PS).

MedidAs DEL HOLOTIPO $\left(\sigma^{7}\right)$. Longitud: total ( $\sin$ rostro) $4,60 \mathrm{~mm}$, rostro $0,50 \mathrm{~mm}$, escapo $1,08 \mathrm{~mm}$, funículo 1,20 (desmómeros I-IV respectivamente $0,26 / 0,27 / 0,14 / 0,14 \mathrm{~mm})$, maza $0,42 \mathrm{~mm}$, ojo $0,28 \mathrm{~mm}$, pronoto $1,10 \mathrm{~mm}$, élitros $3,2 \mathrm{~mm}$, tibias (pro-/meso-/meta-) 1,23/1,10/1,34 mm. Anchura: cabeza (a nivel de los ojos) 0,92 $\mathrm{mm}$, (interocular) $0,52 \mathrm{~mm}$; rostro (a nivel de los pterigios) $0,58 \mathrm{~mm}$, (mínimo dorsal) 0,39 mm (mínimo ventral) 0,56 $\mathrm{mm}$; escapo $0,09 \mathrm{~mm}$, maza $0,12 \mathrm{~mm}$, ojo $0,24 \mathrm{~mm}$, pronoto (anterior /máxima /posterior) 1,00/1,35/ $1,20 \mathrm{~mm}$ y élitros (máxima) 2,30 mm. Altura: abdomen 1,75 $\mathrm{mm}$.

DESCRIPCIÓN. Machos: Longitud: 4,1-4,8 mm. Laparocerus pequeño, ovalado y convexo. Tegumento brillante, de color general pardo oscuro, en patas testáceo más o menos infuscado; vestimenta de escamitas piliformes hialinas poco conspicuas, dominadas por escamitas lanceoladas adpresas de color testáceo con visos cobrizos o dorados, que forman dibujo teselado en los élitros; éstos con setas cortas tumbadas muy poco aparentes.

Antenas mediocres; escapo 0,9x la longitud del pronoto, curvado a la mitad, a partir de ahí progre- 


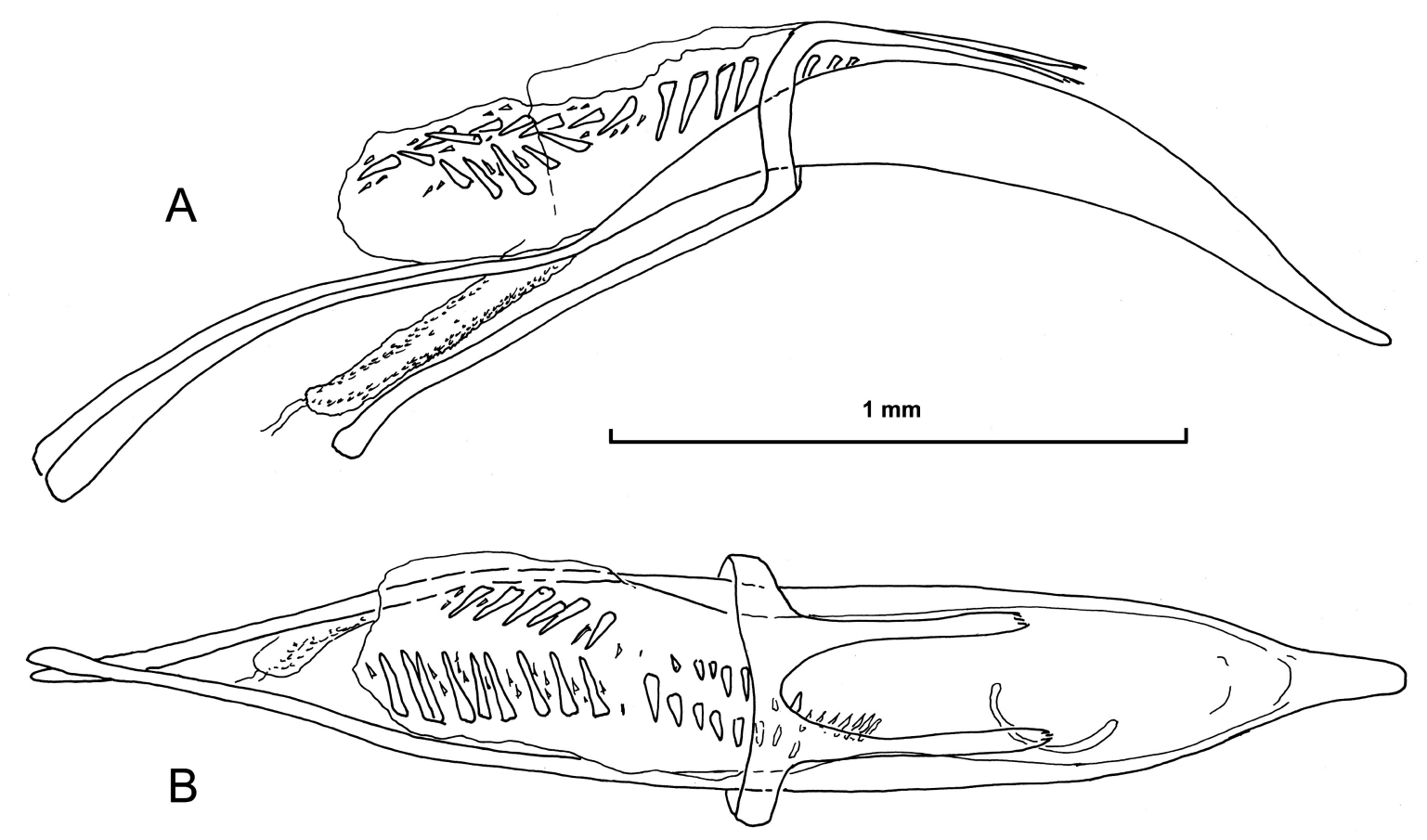

Fig. 5.- Edeago de Laparocerus juelensis n. sp. en vista lateral (A) y dorsal (B).

Fig. 5.- Aedeagus of Laparocerus juelensis n. sp. in lateral view (A) and dorsal view (B).

sivamente engrosado hacia el ápice (subclavulado); desmómeros 1 y 2 casi iguales, maza fusiforme, $(\mathrm{L} / \mathrm{A}=3,5)$ de punta aguda, más larga que los tres últimos desmómeros reunidos.

Cabeza cónica; de cuello ancho, rostro corto (L/A $=0,8)$ trapezoidal: prorrostro bien delimitado, quilla epistomal en V completa y levantada, área paraepistomal deprimida, sin puntear; pterigios cortos, poco salientes; metarrostro con dorso muy estrangulado anteriormente (base antenal visible desde arriba), márgenes gruesos, no levantados, frente ampliamente deprimida, con foseta frontal romboidal muy corta, profunda, no prolongada hacia atrás ni adelante, emplazada a nivel de la mitad posterior de los ojos; vértex poco convexo, prácticamente formando el mismo plano que la frente; tegumento liso, brillante, con puntos separados, rugoso en las sienes. Ojos subesféricos $(\mathrm{L} / \mathrm{A}=1,6)$, convexos $(30-42 \%)$, no pedunculados, con surco periocular superior marcado.

Pronoto convexo, transversal $(\mathrm{L} / \mathrm{A}=0,8)$, sin rebordes, lados moderadamente curvados, máxima anchura algo por detrás de la mitad, constricción premarginal anterior notable, el margen ligeramente levantado al medio. Tegumento liso, con punteado uniforme de puntos gruesos profundos, precisos, poco separados entre sí (1/3-1/2 diámetros); vestimenta de escamitas lanceoladas concentradas hacia los márgenes laterales, borde anterior y en el área basal media convergiendo sobre el escudete, el disco con escamitas piliformes hialinas; sin línea media.

Escudete triangular, tapizado de escamitas lanceoladas.

Élitros ovales $(\mathrm{L} / \mathrm{A}=1,4), 2,9 \mathrm{x}$ más largos que el pronoto, bastante convexos, de base truncada con hombros apenas desarrollados (carina humeral nula o muy incipiente); lados uniformemente curvados, máxima anchura al centro, redondeado apicalmente. Estrías marcadas por puntos gruesos, profundos, no muy anchos; interestrías apenas o algo convexas, con campos de escamitas lanceoladas interrumpidas por zonas con solo escamitas piliformes (máculas más oscuras), e hileras de setas arqueadas pequeñas y tumbadas hacia atrás (menores que una uña), poco conspicuas, salvo en el tercio apical. 


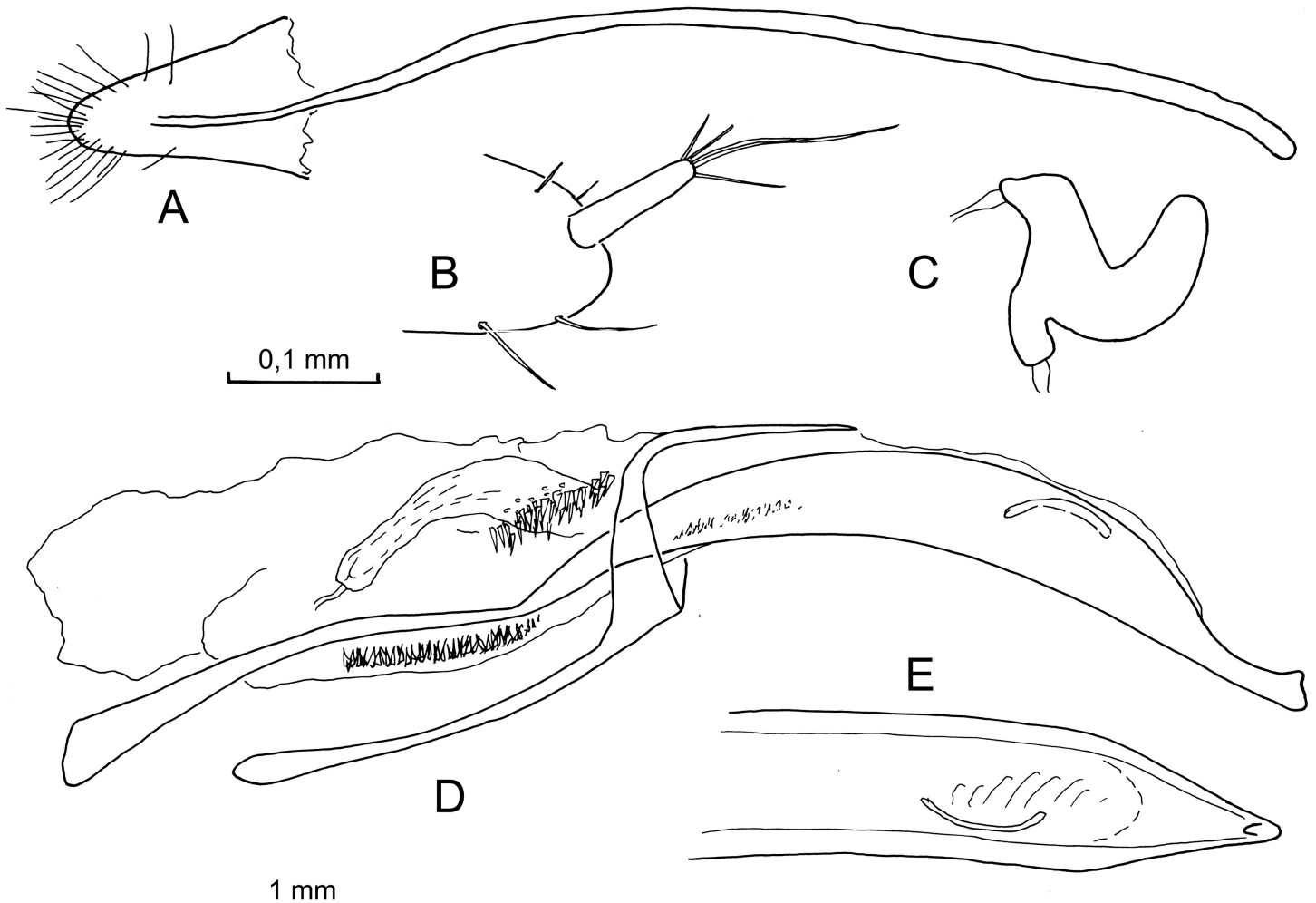

Fig. 6.- Laparocerus rotundatus n. sp. Esternito VIII femenino (A), gonostilo (B), espermateca (C), edeago (D) y detalle del ápice del lóbulo medio (E).

Fig. 6.- Laparocerus rotundatus n. sp. Female sternite VIII (A), gonostylus (B), spermatheca (C), aedeagus (D) and detail of median lobe apex (E).

Patas normales, protibias y mesotibias muy ligeramente arqueadas; protibia no escotada internamente, engrosándose ligeramente hacia el ápice, ángulo apical externo muy redondeado, el interno muy prolongado hacia dentro con fuerte mucrón agudo; mucrón mesotibial algo menor; el metatibial diminuto.

Cara ventral de tegumento negruzco, con pilosidad fina inclinada, uniforme y mediocre, algo más gruesa y densa en los flancos del meso y metasterno. Saliente intermesocoxal corto, apenas levantado. Ventritos 1-2 con microrrugosidad transversal, el resto lisos; el último truncado apicalmente. Convexidad abdominal (H/A) 76\%.

Edeago (Figs. 6D-E) 0,7x la longitud del élitro; lóbulo medio poco arqueado, con punta moderadamente aguzada (vista dorsal), recta y truncada oblicuamente formando una protuberancia característica (vista de perfil). Saco interno en reposo sin rebasar los temones, con campo de dientes proximal y mediano-postmediano (doble) desarrollados, el distal inexistente.

Hembras. Longitud 4,1-4,8 mm. Igual que el macho, incluso en tamaño, pero más ancha en todo y de aspecto más globoso y redondeado. Proporción $\mathrm{L} / \mathrm{A}$ del pronoto $0,67, \mathrm{y}$ del élitro 1,30 . Punteado del pronoto algo menor y, por lo común, algo más separado ( $2 / 3$ de diámetro). Élitros con declive más abrupto, redondeado, y el ápice muy brevemente reflejado; punteado menor e interestrías planas. Último ventrito ojival, no truncado. Esternito VIII, gonostilo y espermateca como en las figuras 6A-C.

ETimología. El nombre de la especie es el participio de perfecto pasivo del verbo latino rotundo $=$ redondeado, en referencia a la terminación de los élitros de las hembras. 
OBSERVACIONES. Laparocerus rotundatus $\mathrm{n}$. $\mathrm{sp}$. está emparentado con L. oculatissimus Machado 2007 y L. exophthalmus Machado 2007, y comparte muchos caracteres con estas dos especies, aunque por su talla pequeña y proporciones más cortas se parece más a la primera que a la segunda (L élitros/ L pronoto $=2,88$ y 3,46 respectivamente). Se distingue de ambas fácilmente por la forma del escapo antenal, engrosado progresivamente a partir de su mitad (pseudo-claviforme) en vez de engrosarse bruscamente en el ápice (capitado). Además, los ojos son notablemente menos sobresalientes (convexidad por debajo del 50\%), nunca subpedunculados; cabeza más ancha con el rostro algo más corto y trapezoidal; el pronoto es menos transversal $\left(O^{\pi}\right)$, con punteado algo menor y más separado; los élitros son más uniformemente convexos, con hombros más reducidos (nunca angulosos) y con los puntos de las estrías menores; las hembras son en relación al macho mucho más anchas, convexas y redondeadas por detrás, con las interestrías elitrales planas y puntos menores, etcétera. El esternito VIII femenino es más parecido al de L. oculatissimus, mientras que el edeago recuerda más al de L. exophthalmus, con la punta recta aunque truncada; el campo de espinas del saco interno presenta un desarrollo intermedio entre estas dos especies.

Para incluir esta nueva especie en la clave de Laparocerus de La Gomera (Machado, 2007b) habría que modificarla del siguiente modo:

3 Scape clavate (progressively and smoothly swollen towards the apex); elytra always with vestiture of scales

Size $>5 \mathrm{~mm}$, body elongate .. 3'

- Size $<5 \mathrm{~mm}$, body short L. rotundatus $\mathrm{n} . \mathrm{sp}$.

DistRIBUCiÓN Y ECOLOGÍA. Especie endémica de La Gomera, encontrada de momento en una localidad de la vertiente meridional seca de la isla, a altitud media $(600 \mathrm{~m})$, en hábitat de tabaibal abierto. Insecto aparentemente invernal que se alimenta al menos de Argyranthemum frutescens (Asteraceae) y Rumex lunaria (Polygonaceae).

\section{Laparocerus pilosiventris $\mathbf{n}$. $\mathbf{s p}$.} (Figs. 4C y 7A-E)

Material examinado. Holotipo: La Gomera, infra Alajeró, $650 \mathrm{~m}$ (UTM 28R 02805603104954$) 10^{7}$ leg. A. Machado (TFMC/CO-15952)._- Paratipos: misma localidad y fecha, 85 exx leg. A. Machado (AMC, 2 NHM), 9 exx ibidem 5-12-2009 leg. P. Stüben (PS).

MEDIDAS DEL hOLOTIPO $\left(0^{T}\right)$. Longitud: total ( $\mathrm{sin}$ rostro) $5,50 \mathrm{~mm}$, rostro $0,66 \mathrm{~mm}$, escapo $1,38 \mathrm{~mm}$, funículo 1,68 (desmómeros I-IV respectivamente $0,34 / 0,40 / 0,25 / 0,18 \mathrm{~mm})$, maza $0,52 \mathrm{~mm}$, ojo $0,42 \mathrm{~mm}$, pronoto $1,12 \mathrm{~mm}$, élitros $4,0 \mathrm{~mm}$, tibias (pro- /meso- /meta-) 1,50/1,36/1,60 mm. Anchura: cabeza (a nivel de los ojos) $0,88 \mathrm{~mm}$, (interocular) $0,52 \mathrm{~mm}$; rostro (a nivel de los pterigios) $0,71 \mathrm{~mm}$, (mínimo dorsal) 0,41 mm (mínimo ventral) 0,64 $\mathrm{mm}$; escapo $0,17 \mathrm{~mm}$, maza $0,18 \mathrm{~mm}$, ojo $0,30 \mathrm{~mm}$, pronoto (anterior /máxima /posterior) 1,05 / 1,57/ $1,30 \mathrm{~mm}$ y élitros (máxima) 2,65 mm. Altura: abdomen $1,90 \mathrm{~mm}$.

DESCRIPCIÓN. Machos: Longitud: 4,7-5,6 mm. Laparocerus de talla mediocre, de aspecto ovalalargado, bastante convexo. Tegumento brillante de color pez, salvo extremidades testáceas, más o menos oscurecidas. Pilosidad bastante uniforme, formada por escamitas piliformes tumbadas y dirigidas hacia atrás, separada lateralmente y solapada a lo largo, de color crema con visos dorados, cobrizos o glaucos; en los élitros alternando parches más y menos densos en las interestrías impares (dibujo más o menos marcado); sin setas sobresalientes.

Antenas largas, escapo 1,5x la longitud del pronoto, curvado al centro, fuertemente engrosado en el cuarto apical; funículo 1,2x la longitud del escapo, $1^{\text {er }}$ desmómero algo más largo que el $2^{\circ}$, el $3^{\circ}$ más largo que el $4^{\circ}$; maza fusiforme, robusta, $2,9 \mathrm{x}$ más larga que ancha, tan o apenas más larga que los tres desmómeros precedentes reunidos.

Cabeza cónica, de base tan ancha como a nivel de los ojos; rostro casi tan largo como ancho en la base, estrechado dorsalmente (sección trapezoidal), de márgenes cóncavos, pterigios bastante sobresalientes, base de las antenas visible desde arriba; prorrostro en declive débil, sin pilosidad ni puntos, y la quilla epistomal poco desarrollada; metarrostro algo deprimido al medio, surcado a lo largo por una línea mediana superficial prolongada hasta el vértex; frente no particularmente deprimida, foseta frontal estrecha y corta; tegumento con puntos precisos, separados, de grosor variable, muy reducidos en el vértex y occipucio. Ojos bastante grandes, ovales, moderadamente prominentes (convexidad $38 \%$ ), próximos al borde frontal, separados por surco periocular profundo.

Pronoto muy transversal $(\mathrm{L} / \mathrm{A}=0,7)$ bastante convexo; lados uniforme y bastante redondeados, 


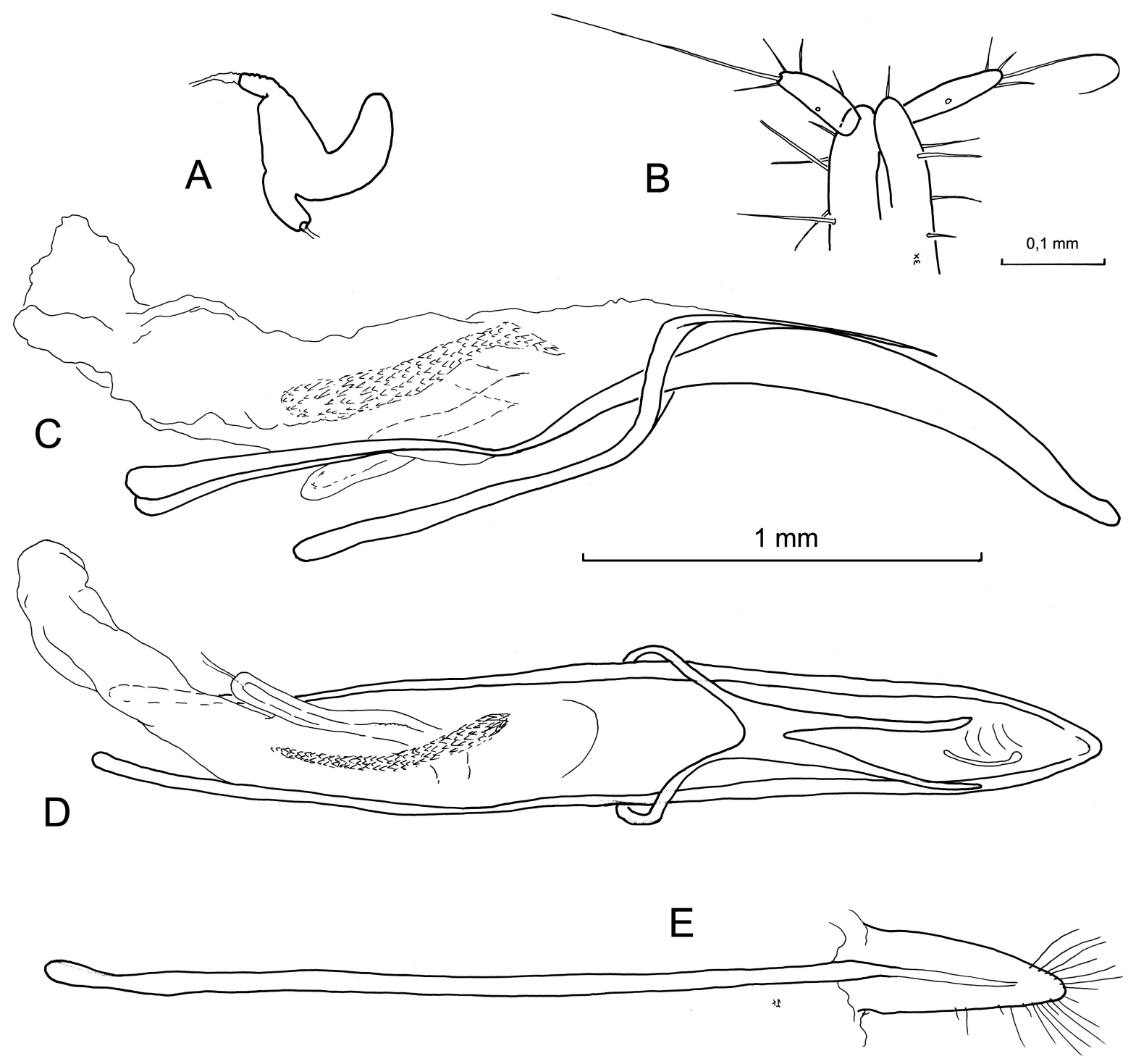

Fig. 7.- Laparocerus pilosiventris n. sp. Espermateca (A), gonostilo (B), edeago en vista lateral (C) y dorsal (D) y esternito VIII femenino (E).

Fig. 7.- Laparocerus pilosiventris n. sp. Spermatheca (A), gonostylus (B), aedeagus en in lateral view (C), aedeagus in dorsal view (D) and female sternite VIII (E).

máxima anchura a la mitad: base con reborde marcado; línea media estrecha, incompleta, a veces ligeramente abultada. Tegumento con puntos gruesos y precisos separados un diámetro entre sí (con escamas piliformes): algunos puntos diminutos en los intervalos.

Escudete triangular, liso, con unas pocas escamas.
Élitros oval-alargados $(\mathrm{L} / \mathrm{A}=1,5)$, de convexidad notable y bastante uniforme, 3,6x más largos y $1,7 \mathrm{x}$ más anchos que el pronoto; poco arqueado lateralmente en su tramo medio, ápice no acuminado, en declive bastante abrupto; hombros prácticamente ausentes. Estrías marcadas por puntos gruesos apenas mayores que los del pronoto; interestrías planas, brillantes, con microrreticulación 
superficial ancha, transversal e irregular; micropuntos poco conspicuos; escamitas piliformes tumbadas, alguna más erguida en el ápice.

Patas delgadas y gráciles. Fémures gruesos, con estrangulamiento preapical interno abrupto y marcado (reborde lateral del acetábulo articular laminar, sobresaliente). Protibias delgadas, el ápice curvado en gancho hacia dentro (ángulo externo ampliamente redondeado), con mucrón (premucrón) fuerte, estrecho y prominente; almohadilla tibial interna apenas desarrollada. Mesotibia en el ápice ensanchada y truncada oblicuamente, con mucrón estrecho y fuerte, algo menor que el protibial. Metatibias ligeramente arqueadas en el plano sagital, truncadas oblicuamente, sin mucrón. Tarsos grandes, algo más anchos que las tibias al medio.

Cara ventral punteada, con microrrugosidad transversal apretada, aparente, salvo en los ventritos apicales; pilosidad fina erguida, algo inclinada, muy desarrollada (doble de larga) y llamativa en las coxas, parte media del mesosterno y a lo largo de la base de los fémures, a modo de cepillo. Saliente mesocoxal estrecho, poco desarrollado, con pilosidad larga. Último ventrito truncado apicalmente.

Edeago (Figs. 7C-D). Lóbulo medio bastante rectilíneo terminado en punta aguzada y roma en visión dorsal, y ligeramente sinuosa y sagitada dorsalmente, vista de perfil; saco interno algo más largo que los temones (en posición de reposo), con un único campo mediano alargado de dentículos, el divertículo gonoporal largo implantado ventrolateralmente por el lado izquierdo

Hembras. Longitud 4,6-5,8 mm, más convexas que el macho, de aspecto más ancho, con élitros más paralelos e inflados; mucrón pro y mesotibial más pequeño, reducido; cara ventral sin mechones ni cepillos de pelos largos; último ventrito con ápice ojival. Espículo ventral de la genitalia con placa estrecha provista de setas muy largas (Fig. 7E); espermateca (Fig. 7A), gonostilo (Fig. 7B).

ETIMOlogía. El nombre específico pilosiventris es un adjetivo latino que hace referencia a la característica pilosidad larga del mesosterno y fémures masculinos.

OBSERVACIONES. La nueva especie es fácil de distinguir de las demás que habitan en La Gomera, por su talla mediana y forma oval-alargada de los élitros carentes de setas erguidas sobresalientes, incluso en el tercio apical. Esta combinación solo se repite en Laparocerus orone Machado 2007, pero en este último los élitros son acuminados en el ápice, los ojos mucho menores, la frente claramente hundida de lado a lado, el punteado del pronoto es más grueso y apretado, y, sobre todo, no presenta la pilosidad ventral larga en los fémures, coxas y mesosterno, tan llamativos en los machos de $L$. pilosiventris $\mathrm{n}$. sp. Este carácter se repite en Laparocerus bacalladoi Machado 2005, que habita en la zona sur de la isla de Tenerife, y además de por su forma en general, la estructura del edeago apunta también hacia una relación de parentesco estrecha. Sin embargo, L. bacalladoi porta abundantes setas largas en todo el élitro, lo que permite resolver cualquier posible confusión.

Para incluir esta nueva especie en la clave de Laparocerus de La Gomera (Machado, 2007b) habría que modificarla del siguiente modo:

19 Elytra with long and thin erect hairs ........................ 20

- Elytra without long and thin erect hairs, with or without setae ...19'

19' Elytra without additional setae; male femora with long hairs along ventral side ...................... L. pilosiventris n. sp. - $\quad$ Elytra with or without additional setae; male femora devoid of long hairs 23

DistRIBUCiÓN Y ECOLOGÍA. Especie endémica de La Gomera, encontrada junto con L. rotundatus $\mathrm{n}$. sp. en la vertiente meridional seca de la isla, a altitud media $(600 \mathrm{~m})$, en hábitat de tabaibal abierto. De momento se conoce de solo una localidad, pero nada justifica que su distribución no sea más extensa. Insecto aparentemente invernal, colectado en abundancia sobre Rumex lunaria (Polygonacea) y Carduus sp (Asteraceae); algunos subidos sobre Ficus carica (Moraceae) y Euphorbia regis-jubae (Euphorbiacea).

\section{Laparocerus magnificus $\mathbf{n}$. sp.}

(Figs.8A y 9A-D)

Material eXaminado. Holotipo: La Gomera, Tamargada, Lomo Palomos, 600 m (UTM 28R 280991 3120320) 10 leg. A. Machado (TFMC/CO-15953).- Paratipos: misma localidad y fecha, 22 exx, 4 exx (uno inmaturo) 7-12-2002 leg. A. Machado (AMC), 4 exx leg. P. Stüben (PS), 2 exx 8-12-2002 leg. R. García (RGB). Juego de Bolas, 600 m 1 ex 18-4-2000; Las Rosas, 500 m 2 exx 7-12-2002 leg. A. Machado (AMC), 1 ex 14-2-2003 leg. P. Oromí (ULL), 1 ex 19-3-1985 leg. E. Colonnelli (MZUR). - No paratipos: El Rejo, 750 m 1 ex 194-2000; Hermigua: Ermita de San Juan 650 m, 4 exx 9-122006, 1 ex 11-2-2006, 1 ex 19-2-2007; Vallehermoso: Piedra Encantada 2 exx 17-2-2004 leg. A. Machado (AMC).

MedidAs DEL HOLOTIPO ( $\left(\sigma^{\top}\right)$. Longitud: total ( $\sin$ rostro) $7,4 \mathrm{~mm}$, rostro $0,76 \mathrm{~mm}$, escapo $2,03 \mathrm{~mm}$, 


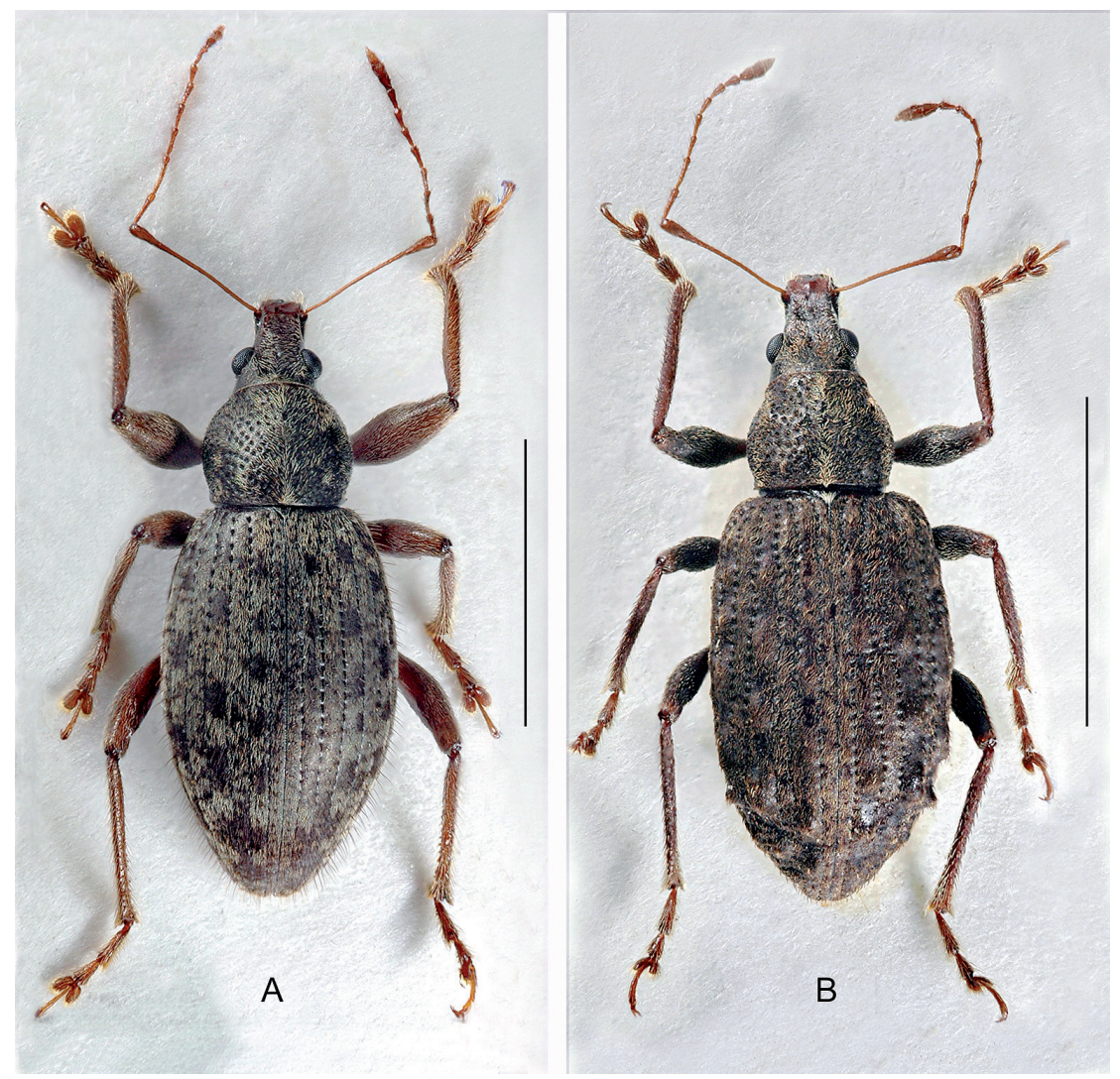

Fig. 8.- Holotipos $0^{7}$ de Laparocerus magnificus n. sp. (A) y Laparocerus mateui tuberosus n. spp. (B). Escala 4 mm.

Fig. 8.- Holotypes $\sigma^{7}$ of Laparocerus magnificus n. sp. (A) and Laparocerus mateui tuberosus n. spp. (B). Scale 4 mm.

funículo 2,65 (desmómeros I-IV respectivamente 0,52 / 0,55 / 0,40/0,36 mm), maza $0,66 \mathrm{~mm}$, ojo $0,46 \mathrm{~mm}$, pronoto $1,80 \mathrm{~mm}$, élitros $5,18 \mathrm{~mm}$, tibias (pro-/meso- /meta-) 2,55/2,15/2,60 mm. Anchura: cabeza (a nivel de los ojos) 1,27 mm, (interocular) $0,65 \mathrm{~mm}$; rostro (a nivel de los pterigios) $0,73 \mathrm{~mm}$, (mínimo dorsal) $0,52 \mathrm{~mm}$ (mínimo ventral) 0,68 $\mathrm{mm}$; escapo $0,16 \mathrm{~mm}$, maza $0,16 \mathrm{~mm}$, ojo $0,30 \mathrm{~mm}$, pronoto (anterior /máxima /posterior) 1,22 / 2,12/ $1,90 \mathrm{~mm}$ y élitros (máxima) $3,30 \mathrm{~mm}$. Altura: abdomen 2,80 $\mathrm{mm}$.

DESCRIPCIÓN. Machos: Longitud: 6,5-9,3 mm. Laparocerus generalmente grande (media $=8,3$ $\mathrm{mm}$ ), de aspecto elíptico-alargado. Tegumento semimate, de color pardo oscuro, más claro (a veces algo rojizo) en las extremidades. Vestimenta de escamitas lanceoladas estrechas, cortas, adpresas, contiguas, de color glauco y dorado, o bien hia- linas y muy finas (piliformes) emplazadas en parches oscuros de extensión variable en el pronoto e interestrías impares del élitro.

Antenas muy largas y gráciles; escapo más largo que el pronoto, muy delgado, prácticamente rectilíneo, suavemente capitado en el cuarto apical; desmómeros I y II del funículo subiguales, el IV menor que el III y mayor que el V; maza fusiforme y delgada $(\mathrm{L} / \mathrm{A}=4,1)$, algo menor que la longitud de los tres desmómeros precedentes reunidos.

Cabeza pequeña y estrecha; rostro de aspecto alargado (tan largo como ancho en la base), poco estrechado dorsalmente, de lados subparalelos; pterigios apenas salientes; quilla epistomal prolongada débilmente al medio hasta el doble arco que delimita el prorrostro (tegumento sin puntos); metarrostro de bordes laterales romos, no acanalado, algo deprimido apicalmente e indicio de carina 


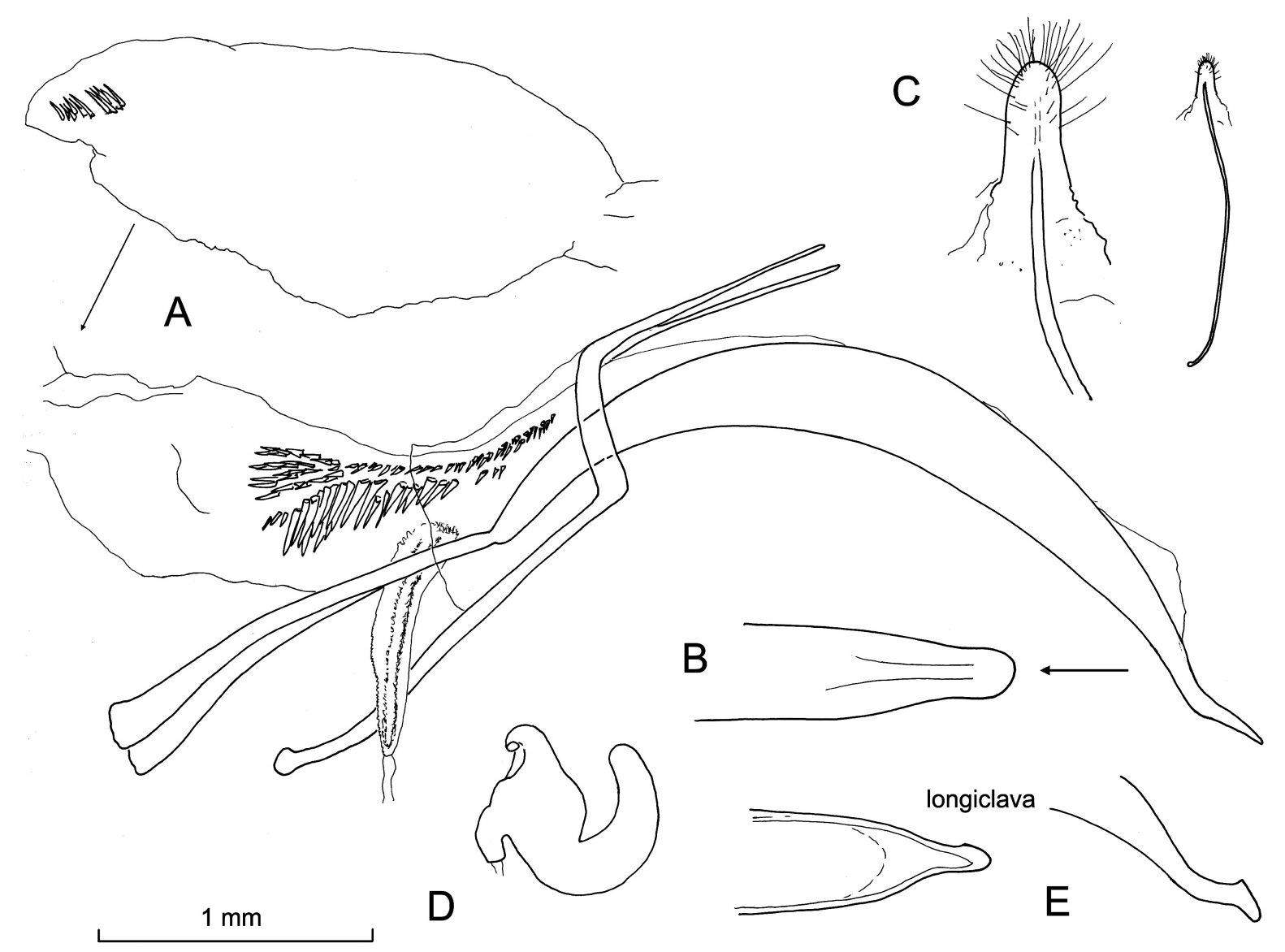

Fig. 9.- Laparocerus magnificus n. sp. Edeago visto de perfil (A) y detalle del ápice del lóbulo medio (B); esternito VIII femenino (C) y espermateca (D). Laparocerus longiclava Lindberg, 1953, detalle del ápice del lóbulo medio del edeago en visión dorsal y lateral $(\mathrm{E})$.

Fig. 9.- Laparocerus magnificus n. sp. Aedeagus in lateral view (A) and detail of median lobe apex (B); female sternito VIII (C) and spermatheca (D). Laparocerus longiclava Lindberg, 1953, detail of the median lobe apex in lateral and dorsal view (E).

mediana; frente ligeramente deprimida, fóvea muy pequeña; vértex poco convexo. Tegumento con microrreticulación isodiamétrica bien impresa, con punteado abierto, destacado (algunos puntos mayores en el vértex); escamitas piliformes largas, suberectas (ver de perfil). Ojos grandes, oval-alargados $(\mathrm{L} / \mathrm{A}=1,5)$, oblicuos, y algo excéntricos (cénit desplazado hacia atrás); surco periocular superior marcado, tangente al borde de la frente.

Pronoto transversal $(\mathrm{L} / \mathrm{A}=0,85)$ subgloboso, de lados curvos, sin reborde, con anchura máxima al centro o algo por delante; tegumento fuertemente microrreticulado, con puntos mediocres, profundos, bien delimitados, separados 1-1,5 diámetros entre sí (más gruesos y juntos en la región postero-lateral, y menores y más escasos hacia el margen anterior); línea media apenas insinuada; setas suberectas emergentes inclinadas hacia atrás (ver de perfil).

Escudete triangular, cubierto de escamitas.

Élitros elípticos $(\mathrm{L} / \mathrm{A}=1,6)$, poco convexos, truncados en la base, 2,9x más largos y 1,6x más anchos que el pronoto; ángulo humeral romo con incipiente callosidad humeral (hombros algo marcados); estrías definidas por puntos estrechos, longitudinales; interestrías planas con 12-15 escamitas adpresas a lo ancho e hileras irregulares de 1-2 setas largas, suberectas, de color pardo y longitud bastante homogénea (siempre bastante más largas 
que una uña); tegumento mate con microrreticulación diminuta, indistinta.

Patas largas y gráciles; fémures con pilosidad larga sobresaliente en su cara inferior (mitad basal), el profémur notablemente inflado; protibias delgadas, moderadamente curvadas hacia dentro en su tercio apical; ángulo apical externo romo, el interno expandido hacia dentro, con pequeño mucrón agudo, pilosidad abundante e incipiente cepillo anteapical (hilera de pelos más largos, sobresalientes, más largos que el diámetro tibial). Mesotibias con pilosidad similar y mucrón pequeño; metatibias con mucrón muy pequeño y una decena de dientes de sierra a lo largo del canto interno. Tarsos grandes, tarsómeros I-II largos y estrechos.

Cara ventral con escamitas adpresas no muy densas (salvo flancos del tórax), sin pilosidad accesoria; saliente mesoesternal estrecho y apenas levantado; último ventrito truncado, muy ligeramente escotado, con algunos puntos submarginales.

Edeago (Fig. 9A), visto de perfil, bastante arqueado y con la punta marcadamente sinuosa (ancha y roma en visión dorsal: Fig. 9B). Saco interno muy largo y voluminoso; divertículo gonoporal largo y estrecho, emplazado ventro-lateralmente, con espículas diminutas que definen dos líneas longitudinales a modo de incipientes flagelos; un campo doble y extenso de dientes en su tramo medio, y uno apical par o triple muy pequeño en el fondo del divertículo ciego.

Hembras: Longitud 7,6-9,4 mm. Igual que el macho, pero notablemente más anchas (L/A pronotal $=0,8 ; \mathrm{L} / \mathrm{A}$ elitral $=1,35$ ), con los élitros mucho más deprimidos y los hombros bien desarrollados. Las tibias son inermes y la protibias rectilíneas, sin cepillos ni dientes; profémures más delgados. Último ventrito con ápice ojival. Espículo ventral de la genitalia muy largo, con placa muy estrecha (Fig. 9C). Espermateca (Fig. 9D).

Etimología. El epíteto específico latino magnificus, un adjetivo con igual significado de magnífico o espléndido en español, hace referencia al aspecto del insecto, que destaca por el porte entre sus congéneres más próximos.

Comentario diagnóstico. A primera vista, la nueva especie puede confundirse con Laparocerus sanchezi Roudier, 1957 o L. longiclava Lindberg, 1953. De la primera se distingue por su cuerpo más robusto y alargado, rostro más paralelo, élitros más deprimidos en la base, menos ovoides y con hombros incipientes en los machos y bien desarrollados en las hembras (ausentes en ambos sexos en L. sanchezi). La pilosidad fina y larga que ambas especies comparten en cabeza, pronoto y élitros es menos densa y más homogénea en L. magnificus n. sp., mientras que en $L$. sanchezi se mezclan pelos de longitud variable (muy evidente en el área humeral). En esta última especie la pilosidad de las tibias y fémures está muy desarrollada y es más erguida, mientras que en L. magnificus es más corta, más inclinada y solo sobresale llamativamente en la cara ventral de los profémures. Además, las metatibias masculinas no son lisas, sino que presentan dientes de sierra bien desarrollados a lo largo de su canto interno. El edeago (Fig. 6A) es prácticamente igual y apunta hacia un parentesco estrecho entre ambas especies. La única diferencia notoria es la presencia en L. magnificus n.sp. de espinas apicales en el divertículo ciego del saco interno.

La forma del cuerpo se parece más a la de $L$. longiclava, aunque esta especie es menos robusta, de élitros algo más estrechos y subparalelos, con las interestrías en los machos más convexas y los puntos de las estrías mucho más gruesos (tanto como los del pronoto). La diferencia más evidente es la ausencia de pilosidad en la cabeza y el pronoto, y en los élitros es más reducida y recia, sobre todo en la mitad anterior (setas finas nunca más largas que una uña). También en los fémures la pilosidad es más reducida, uniforme y adpresa, y los élitros de las hembras presentan sendas protuberancias subapicales, ausentes en L. magnificus $\mathrm{n}$. sp. El ápice del lóbulo medio del edeago es muy diferente, estrecho e inclinado hacia un lado en L. longiclava (Fig. 9E), y ancho, romo y simétrico en L. magnificus n. sp. (Fig. 9B).

Para incluir esta nueva especie en la clave de Laparocerus de La Gomera (Machado, 2007b) habría que modificarla del siguiente modo:

20 Long hairs restricted to elytra 21

Long hairs extending over head, pronotum and elytra .. 20

20' Elytra ovoid, without shoulders in both sexes and with two apical tumefactions in females. Male metatibiae without denticles on inner face

L. sanchezi Roudier, 1957

- $\quad$ Elytra more parallel and depressed at base, with shoulders (small in males, large in females) and without apical tumefactions. Male metatibiae with denticles on inner face L. magnificus $\mathrm{n}$. $\mathrm{sp}$.

DISTRIBUCIÓN Y ECOLOGÍA. Laparocerus magnificus n. sp. es endémico de La Gomera y habita un 
tramo de las medianías (500-700 m de altitud) de la vertiente septentrional de la isla. Se ha colectado básicamente sobre Artemisia thuscula (Asteraceae) en hábitat de matorral o margen del bosque, y es posible que esté vinculada a la biocenosis del depauperado bosque termófilo. El área de distribución no se solapa con la de su probable adelfotaxon $L$. sanchezi, mucho más extensa abarcando la parte central de la isla y vertiente de sotavento, ni es tan común ni eurioica como él.

\section{Laparocerus mateui tuberosus $\mathbf{n}$. ssp.}

(Figs. 8B y 10A-E)

Material eXAminado. Holotipo: El Hierro: El Gretime, $825 \mathrm{~m}$ (UTM 28R 01971 30719), $10^{\pi}$ 5-12-1999 leg. A. Machado (TFMC/CO-15957).- Paratipos: misma localidad, 19 exx 512-1999, 40 exx 7-12-1999 leg. A. Machado (AMC, $1 \mathrm{MNH}$ ). Pista al Derrabado, 750 m, 1 ex 29-12-1998 leg. P. Stüben (PST); idem. 796 m 22-12-2006, 8 exx, 13 exx 5-12-2008 leg. A. Machado (AMC). Pista de Mencáfete [= al Derrabado] 5 exx 5-12-1999, 35 exx 5-12-2008 leg R. García (RGB), 24 exx. 5-12-2008, leg. A. Aguiar (AAC).

MedidAS DEL HOLOTIPO $\left(\sigma^{7}\right)$. Longitud: total ( $\sin$ rostro) $7,40 \mathrm{~mm}$, cabeza $1,50 \mathrm{~mm}$, rostro $0,80 \mathrm{~mm}$, escapo $1.90 \mathrm{~mm}$, funículo 2,30 (desmómeros 1-4 respectivamente 0,48 / 0,48 / XX/ XX mm), clava $0,60 \mathrm{~mm}$, pronoto $1,55 \mathrm{~mm}$, élitros $5,20 \mathrm{~mm}$, tibias (pro- /meso- /meta-) 2,65/2,25/2,65 mm. Anchura: cabeza (a nivel de los ojos) 1,20 mm (entre los ojos) $0,72 \mathrm{~mm}$, rostro (a nivel de los pterigios) $0,77 \mathrm{~mm}$, rostro (mínimo dorsal /ventral) $0,50 / \mathrm{XX} \mathrm{mm}$, rostro (base) $0,77 \mathrm{~mm}$, escapo $0,05 \mathrm{~mm}$, clava $0,19 \mathrm{~mm}$, pronoto (anterior /máxima /posterior) 1,35/1,93/ $1,75 \mathrm{~mm}$ y élitros (máxima) 3,15 mm. Altura: abdomen $2,35 \mathrm{~mm}$.

DiAgNOSIS DIFERENCIAL: Longitudes $\sigma^{7} \sigma^{7}=7,2$ $8,6 \mathrm{~mm}$, 우 $ᄋ=7,7-8,9 \mathrm{~mm}$. Aspecto muy parecido a la subespecie tiponominal de la vecina isla de La Gomera. Machos con élitros algo más curvados lateralmente (menos paralelos) y carina humeral y tubérculos menos desarrollados; punteado del pronoto más preciso y regularmente distribuido (en ssp. mateui puntos generalmente mayores y menos definidos sobre tegumento algo abollado); funículo con desmómeros 1-2 casi iguales. Hembras más cortas, con ratio elitral L/A promedio de 1,47 en vez de 1,61; los grandes tubérculos subapicales normalmente agudos y no romos; setas negras en tubérculos e intervalos menos gruesas y más cortas. Ápice del lóbulo medio del edeago más recto en visión lateral, con una débil quilla (Fig. 10D): pará- meros más largos. Esternito VIII, espermateca y gonostilo como en las figuras $10 \mathrm{~A}-\mathrm{C}$.

Etimología. El epíteto subespecífico latino tuberosus (= lleno de tubérculos) es un adjetivo que hace referencia a las protuberancias que presentan los élitros del insecto.

OBSERVACIONES. Si se exceptúan algunos miembros del subgénero Fernandezius (antes de Lichenophagus) que son de talla mucho menor y viven en la hojarasca, la especie que nos ocupa es la única conocida del género Laparocerus que presenta protuberancias a lo largo de los élitros, carácter muy llamativo que la hace inconfundible. La mayor curvatura lateral de los élitros y los tubérculos elitrales más agudos en las hembras, sirven para distinguir la nueva subespecie de su vicariante de la isla de $\mathrm{La}$ Gomera, que vive en condiciones semejantes.

DiSTRIBUCIÓN Y ECOLOGÍA. Laparocerus mateui tuberosus n. ssp. es endémico de la isla de El Hierro. Vive en ambientes muy húmedos en la laurisilva que persiste en las laderas occidentales del valle de El Golfo, a altitudes entre los 700-950 metros. Es activo de noche, poco común, y se alimenta principalmente de Cedronella canariensis. y Pericalis appendiculatus (Asteraceae). También se ha colectado sobre Myrica faya (Myricaceae).

\section{Laparocerus bimbache $\mathrm{n}$. sp.}

\section{(Figs. 11B y 12A-C)}

= tessellatus auctt., non Brullé, 1839

Material examinado. Holotipo: El Hierro, El Sabinar $600 \mathrm{~m}$ (UTM 27R 0783214-30726821), O" 11-2-2004 leg. A. Machado (TFMC/CO-15954). - Paratipos: Misma localidad y datos de colecta, 36 exx (AMC), ibidem 5 exx 4-12-1999 leg. R. García (RGB); Las Sabinas, 1 ex (n ${ }^{\circ}$ 1126) leg Franz (NMW).- No paratipos: El Gretime 825 m, 3 exx 5-12-1999; Pista del Derrabado 796 m, 2 exx 22-12-2006; Pista Mencáfete 800 m, 4 exx 5-12-2008; Llanos de Binto 1240 m, 3 exx 11-2-2004; Raya de la Mareta 1220 m, 10 exx 5-12-1999; El Fayal 1350 m, 3 exx 6-12-1999; San Andrés 1100 m, 1 ex 5-2-1982; Piedras Blancas 912 m, 22 exx 23-12-2006; Tiñor 1050 m, 2 exx 5-12-1999, 6 exx 13-2-2004, 6 exx 22-2-2005, 6 exx 7-12-2008; Malpaso 1450 m, 2 exx 11-2-2004; Ladera de El Golfo 1130 m, 4 exx 112-2004; Sendero Jinama 0,5 Km, 4 exx 12-2-2004; Monte Ajares $600 \mathrm{~m}, 2$ exx, leg. A. Machado (AMC). Pista del Derrabado, 3 exx 13-2-2004 leg. Giet; 2 exx 28-8-2007 leg López \& Oromí; Cueva de la Curva 1 ex 13-2-2004 leg. Giet; Sima de Las Palomas, 1 ex 18-4-1985 leg. López \& Oromí (ULL). El Pinar n ${ }^{\circ}$ 1756, 2 exx, no 1917, 7 exx; ca Tiñor n ${ }^{\circ} 1470$, 12 exx; Monte Tifirabe $n^{\circ}$ 1941, 2 exx leg H. Franz (NMW). El Hierro (sin localidad) 8 exx leg Wollaston (8 UMO, 1 NHM), Montaña de la Casilla 900 m, 3 exx 19-1-1998; Lomo Blanco 


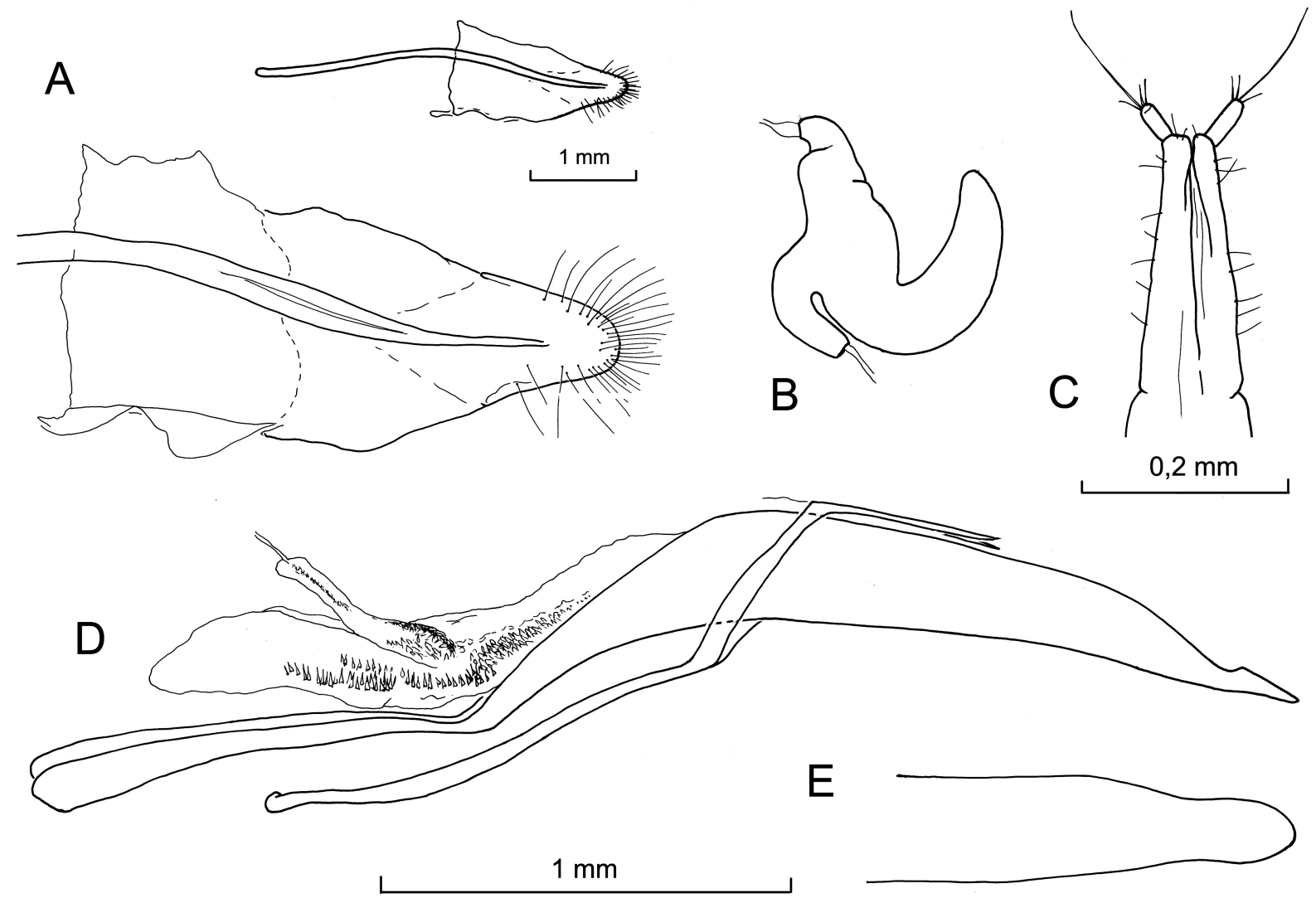

Fig. 10.- Laparocerus mateui tuberosus n. ssp. Esternito VIII femenino (A), espermateca (B), hemisternitos XI con gonostilos $(C)$, edeago (D) y detalle del ápice del lóbulo medio en visión dorsal (E).

Fig. 10.- Laparocerus mateui tuberosus n. ssp. Female sternite VIII (A), spermatheca (B), hemisternite XI with gonostyli $(C)$, aeodeagus (D), and detail of the median lobe apex in dorsal view (E).

550 m, 1 ex 21-1-1998; Timbaromba 1200 m, 12 exx 19-1-1998; El Gretime 800 m, 20-1-1998 leg. L. Behne (DEI).

MEDIDAS DEL HOLOTIPO $\left(\sigma^{7}\right)$. Longitud: total (sin rostro) $3,80 \mathrm{~mm}$, rostro $0,40 \mathrm{~mm}$, escapo $0,90 \mathrm{~mm}$, funículo 0,92 (desmómeros I-IV respectivamente 0,20 / 0,20 / 0,13/0,10 mm), maza 0,38 mm, ojo 0,27 mm, pronoto $0,79 \mathrm{~mm}$, élitros $2,70 \mathrm{~mm}$, tibias (pro- /meso/meta-) 1,02/0,89/1,08 mm. Anchura: cabeza (a nivel de los ojos) $0,81 \mathrm{~mm}$, (interocular) $0,52 \mathrm{~mm}$; rostro (a nivel de los pterigios) $0,51 \mathrm{~mm}$, (mínimo dorsal) 0,36 $\mathrm{mm}$ (mínimo ventral) $0,52 \mathrm{~mm}$; escapo $0,11 \mathrm{~mm}$, maza $0,11 \mathrm{~mm}$, ojo $0,22 \mathrm{~mm}$, pronoto (anterior /máxi$\mathrm{ma} /$ posterior) $0,82 / 1,08 / 0,98 \mathrm{~mm}$ y élitros (máxima) $1,90 \mathrm{~mm}$. Altura: abdomen 1,40 mm.

DESCRIPCIÓN. Machos: Longitud: 3,6-4,6 mm. Laparocerus pequeño de aspecto ovalado, modera- damente convexo. Tegumento pardo-negruzco, sobre todo cabeza y pronoto; extremidades pardorojizas más o menos infuscadas; vestimenta poco densa de escamitas separadas, lanceoladas o piliformes, adpresas o tumbadas, de color dorado, a menudo glaucas o con visos cobrizos, formando dibujo variable en parches claros y oscuros; unas pocas cerdas cortas curvadas hacia atrás y poco conspicuas en la mitad posterior del élitro.

Antenas recias, escapo 1,1x la longitud del pronoto, curvado al medio, y muy engrosado apicalmente $(>1 / 3)$; funículo prácticamente de igual longitud, desmómeros I y II igual de largos, el VII robusto; maza oval alargada, gruesa $(\mathrm{L} / \mathrm{A}=3,4)$, mayor que los tres desmómeros previos reunidos.

Cabeza ancha, robusta, deprimida, de morro corto transversal y aspecto trapezoidal $(\mathrm{L} / \mathrm{A}=0,7)$; 

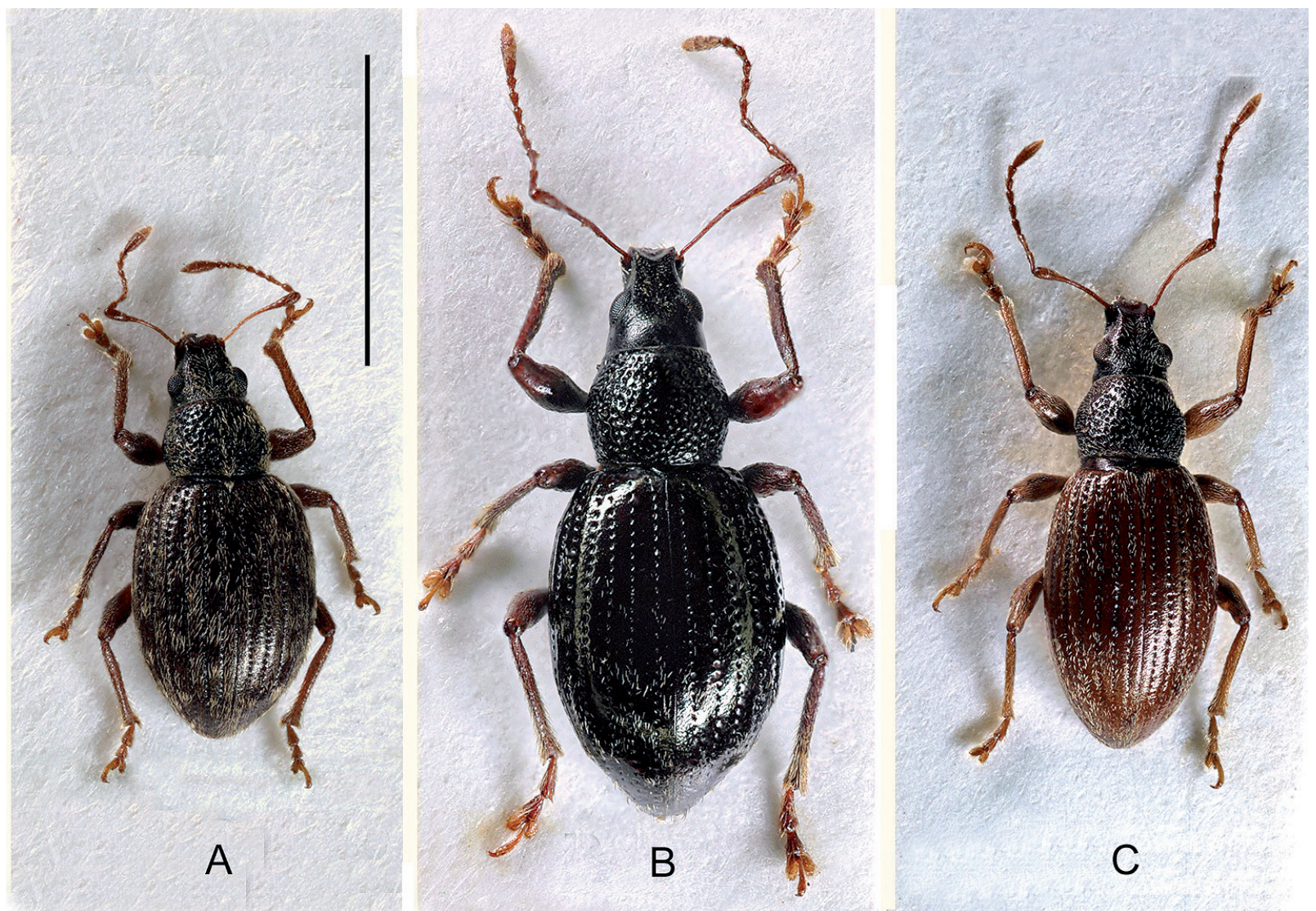

Fig. 11.- Holotipos $0^{7}$ de Laparocerus bimbache n. sp. (A), Laparocerus cephalotes n. sp. (B) y Laparocerus orone hierrensis n. ssp. (C). Escala $=3 \mathrm{~mm}$.

Fig. 11.- Holotypes $\sigma^{7}$ of Laparocerus bimbache n. sp. (A), Laparocerus cephalotes n. sp. (B), and Laparocerus orone hierrensis n. ssp. (C). Scale $=3 \mathrm{~mm}$.

márgenes ventrales subparalelos, los superiores convergentes hacia delante, algo tumefactos; pterigios paralelos, nada salientes (base antenal bien visible desde arriba) prorrostro bien delimitado, brillante; quilla epistomal muy desarrollada, área paraespistomal deprimida, con microrreticulación isodiamétrica; metarrostro deprimido a lo largo, con puntos gruesos en los márgenes y base; frente bastante deprimida, con puntos y rugosidad convergente sobre foseta central, ésta estrecha y longitudinal; escamitas dispersas, largas, tumbadas. Ojos grandes, ovales $(\mathrm{L} / \mathrm{A}=1,2)$, simétricos, moderadamente sobresalientes (convexidad 30\%).

Pronoto transversal $(\mathrm{L} / \mathrm{A}=0,7)$, algo más estrecho por delante que por detrás, sin rebordes; lados bastante arqueados al medio; máxima anchura sobre la mitad; dorso con grandes puntos foveiformes separados menos de un diámetro entre sí (aspecto algo varioloso); interespacios brillantes con micropuntos apenas marcados; línea media incipiente, a modo de gránulo central algo alargado; vestimenta rala de escamitas lanceoladas, concentradas sobre los flancos y en la base a nivel del escudete, zonas con solo escamitas piliformes (hialinas, muy poco conspicuas), se ven como máculas oscuras (tegumento expuesto).

Escudete triangular, tapizado de escamitas doradas.

Élitros ovales $(\mathrm{L} / \mathrm{A}=1,4)$, apicalmente algo acuminados; 3,4x más largos que el pronoto y 1,8x más anchos; lados arqueados, con máxima anchura al medio, base ligeramente cóncava, vista de perfil al mismo nivel que pronoto; hombros obtusos, 

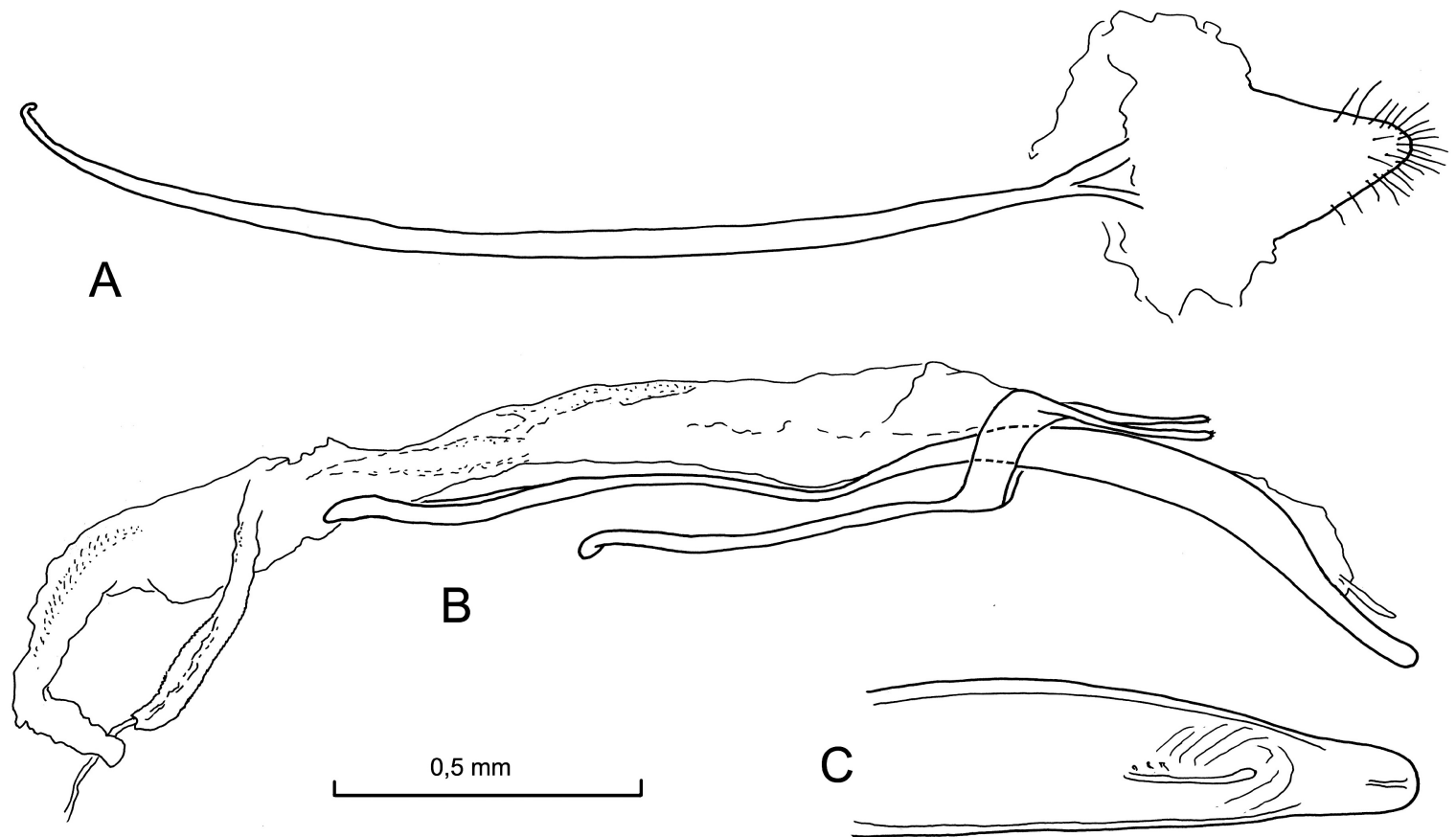

Fig. 12.- Laparocerus bimbache n. sp. Esternito VIII femenino (A), edeago (B y detalle del ápice del lóbulo medio (C).

Fig. 12.- Laparocerus bimbache n. sp. Female sternite VIII (A), aedeagus (B) and detail of median lobe apex (C).

redondeados, nada marcados. Estrías muy aparentes, definidas por puntos profundos, anchos, bastante próximos entre sí (algo menores que los del pronoto); interestrías poco convexas, las suturales ligeramente deprimidas en la base; tegumento brillante, ligeramente chagrinado, visible entre la vestimenta de escamas; las piliformes hialinas, inconspicuas, casi doble de largo que las lanceoladas; setas pardas cortas, arqueadas hacia atrás poco sobresalientes, notorias en la mitad apical.

Patas cortas, normales. Protibia recta, ligeramente escotada por dentro distalmente; ápice con ángulo externo romo, el interno ensanchado hacia dentro, con mucro triangular bien desarrollado (setas mucronales muy largas); mesomucro presente, metamucro minúsculo. Tarsos delicados, lóbulos del $3^{\circ}$ artejo subovoides.

Cara ventral brillante, con puntos gruesos superficiales, y pilosidad rala suberecta y algunas escamitas lanceoladas más concentradas en los flancos del metasterno y menos en los ventritos. Apófisis intermesocoxal muy estrecha, apenas levantada y agudamente aquillada. Ventrito $5^{\circ}$ subtruncado apicalmente.
Edeago (Figs. 12B-C) largo y delicado; lóbulo medio poco arqueado, la punta casi recta, vista de perfil, roma y ancha, en vista dorsal; temones tan largos como el lóbulo medio. Saco interno tubular y largo, rebasando los temones, sin dientes, con campo escamuloso dorsal mediano y otro basal más extenso, poco aparente; esclerito ostiolar recto, en posición mediana; lóbulo gonoporal delgado y bastante largo.

Hembras. Longitud 3,8-5,9 mm. Igual que el macho, pero más globosas. Pronoto algo más ancho en la base y máxima anchura algo por debajo de la mitad; élitros más anchos (1,9x más que el pronoto) e inflados $(\mathrm{L} / \mathrm{A}=1,3)$, con interestrías menos covexas. Tibias inermes (promucro minúsculo). Último ventrito ojival. Placa apical del esternito VIII triangular, con setas largas (Fig. 12A).

ETIMOLOGía. El nombre específico se ha tomado del gentilicio de los aborígenes de la isla de El Hierro, los bimbaches. Es un sustantivo en aposición y, por tanto, invariable.

COMENTARIO. Laparocerus bimbache n. sp. pertenece al grupo de L. tessellatus, cuyos vicariantes 
interinsulares se diferencian muy poco morfológicamente, a pesar de que las distancias genéticas que los separan son considerables $(4,7-6,2 \%$ en secuencias parciales de la mtCOII, datos pendientes de publicación). La nueva especie se parece mucho a L. tessellatus (Brullé, 1839) de Tenerife y, de hecho, se venía asimilando a esta especie. Se puede distinguir de ella por las antenas más cortas, más robustas en la base del escapo y sobre todo distalmente, con el engrosamiento abarcando el $40 \%$ del escapo (en tessellatus el escapo es muy fino en el tramo basal y está capitado en el tercio apical); el tegumento del rostro está más esculpido, con puntos gruesos y microestrías, el paraepistoma y metarrostro deprimidos (en tessellatus con puntos menores, más liso, brillante y uniforme), el punteado del pronoto es mucho más grueso y apretado (en tessellatus es menor, superficial y los puntos están separados más de un diámetro entre sí); los élitros $\sigma^{7} O^{\top}$ son algo más ovales y en las $ᄋ$ 우 menos globosos (elevados) y nada cuadrangulares en la base, como ocurre en tessellatus; las interestrías son menos convexas y las escamitas en general más largas y algo más densas.

Es característico de L. bimbache n. sp. la estrechez y filo aquillado que presenta el saliente intermesocoxal, más ancho y romo en $L$. tessellatus o algo más ancho y no paralelo en $L$. freyi Uyttenboogaart, 1940, la especie con la que está más relacionada (datos moleculares sin publicar), que también es de la isla de Tenerife. En esta última, los élitros son algo más oblongos (lados menos curvados, subparalelos al medio), incluidos los de las hembras, y el punteado del pronoto es notoriamente doble (puntos gruesos y menores no tan diferentes), más apretado y superficial, nada varioloso. La vestimenta de escamas es más uniforme y las escamitas más cortas. No se aprecian diferencias significativas en los edeagos, lo que suele ser bastante habitual en Laparocerus que han evolucionado alopátridamente al segregarse según islas, pero manteniendo el mismo nicho ecológico.

DISTRIBUCIÓN Y ECOLOGÍA. Laparocerus bimbache n. sp. es endémico de la isla de El Hierro. Está bastante distribuido por zona alta y de medianías (500-1450 m de altitud) a barlovento, donde llega influencia húmeda de la capa de nubes de los alisios. No es tan abundante como sus vicariantes de Tenerife, La Palma o Gran Canaria, y se alimenta preferentemente de tagasaste, Chamaecytisus proliferus proliferus (Fabaceae) y jaras, Cistus monspe- liensis (Cistaceae), aunque también se ha colectado sobre Teline sp. (Fabaceae), Rubus ulmifolius (Rosaceae), Erica arborea (Ericaceae), Cedronella canariensis, Micromeria sp. (Labiatae), etc. Es un insecto activo durante la noche.

\section{Laparocerus cephalotes $\mathbf{n}$. sp.}

\section{(Figs. 11B y 13A-E)}

Material eXAminado. Holotipo: El Hierro, Frontera: El Lunchón 350 m (UTM 28R 024579 307319), 10 23-2-2005 leg. A. Machado (TFMC/CO-15955)._ Paratipos: Misma localidad, 12 exx 12-2-2004, 24 exx 23-2-2005 leg. A. Machado (AMC, 1 NHM), 12 exx 4-12-2008 leg. R. García (RGB).- No paratipos: Ajares, camino La Virgen 670 m, 17 exx 6-12-2008; Valverde i. Caldereta 713 m, 5 exx 5-12-2008; Valverde, Cruz del Calvario 565 m 2 exx; Infra Valverde, km 7, 400 m, 3 exx 6-12-1999, 1 ex 3-2-2004; Hoya Grande (zona recreativa) 2 exx 13-2-2004; Tiñor 1000 m, 3 exx 13-2-2004; Guarazoca 400 m, 23 exx 23-2-2005; Caleta, s. Aeropuerto 180 m, 23-2-2005; Pista Mencáfete 800 m, 4 exx 5-12-2008; Sabinosa, La Tabla $200 \mathrm{~m} 2$ exx 5-12-2008 leg. A. Machado (AMC). Malnombre 2 exx 12-4-2004 leg. Oromí; Camino Jinama a Frontera 1 ex 12-2-2004 leg. Oromí \& López (ULL).

Medidas DEL hOlOtiPo ( $\left.\sigma^{\pi}\right)$. Longitud: total (sin rostro) $5,9 \mathrm{~mm}$, rostro $0,62 \mathrm{~mm}$, escapo $1,64 \mathrm{~mm}$, funículo 1,98 (desmómeros I-IV respectivamente $0,46 / 0,52 / 0,22 / 0,22 \mathrm{~mm})$, maza $0,68 \mathrm{~mm}$, ojo $0,48 \mathrm{~mm}$, pronoto $1,35 \mathrm{~mm}$, élitros $4,10 \mathrm{~mm}$, tibias (pro- /meso- /meta-) 1,78 /1,56/1,90 mm. Anchura: cabeza (a nivel de los ojos) 1,05 mm, (interocular) $0,54 \mathrm{~mm}$; rostro (a nivel de los pterigios) $0,70 \mathrm{~mm}$, (mínimo dorsal) 0,48 mm (mínimo ventral) 0,64 $\mathrm{mm}$; maza $0,15 \mathrm{~mm}$, ojo $0,38 \mathrm{~mm}$, pronoto (anterior /máxima /posterior) $1,20 / 1,61 / 1,40 \mathrm{~mm}$ y élitros (máxima) 2,70 mm. Altura: abdomen 2,23 mm.

DESCRIPCIÓN. Machos: Longitud: 5,3-5,9 mm. Laparocerus de tamaño mediocre, oblongo-ovalado, subconvexo, robusto en su mitad anterior. Tegumento brillante o algo alutáceo (cabeza y pronoto), de color negruzco, a veces con ligero viso metálico; extremidades frecuentemente pardas, con tarsos más claros; revestimiento laxo de escamitas adpresas lanceoladas pequeñas, de color testáceo o glauco, con visos cobrizos o verdes, formando algunas teselas claras, sobre todo en los flancos y ápice elitral; éstos con cerdas negras pequeñas suberectas y separadas, más conspicuas en la mitad apical.

Antenas largas, gráciles; escapo 1,2x la longitud del pronoto, ligeramente sinuoso en el tercio basal, capitado en el tercio apical; funículo $1,2 \mathrm{x}$ la longitud del escapo, desmómero I normalmente mayor 


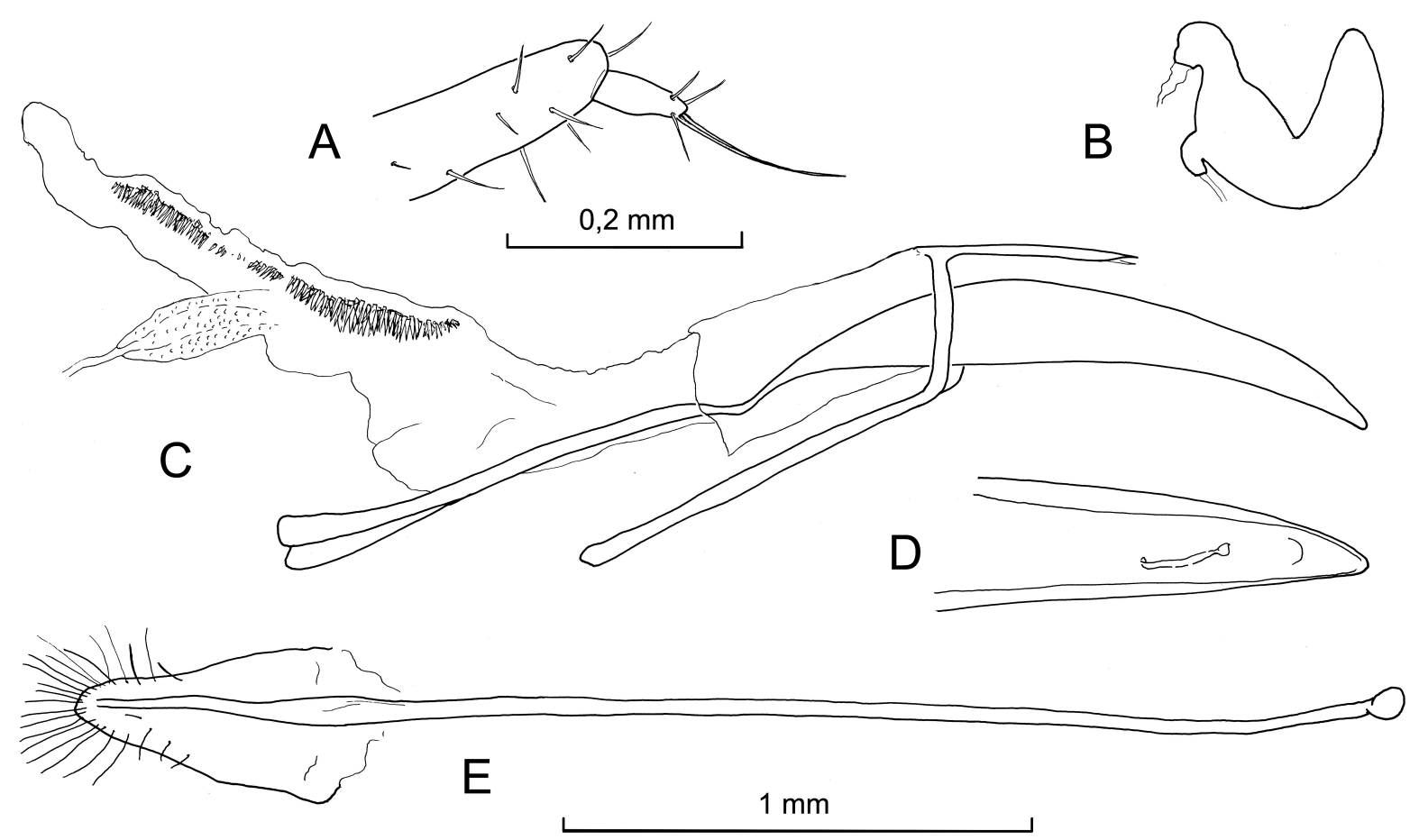

Fig. 13.- Laparocerus cephalotes n. sp. Gonostilo (A), espermateca (B), edeago (C), detalle del ápice del lóbulo medio (D) y esternito VIII femenino (E).

Fig. 13.- Laparocerus cephalotes n. sp. Gonostylus (A), spermatheca (B), aedeagus (C), detail of median lobe apex, (D) and female sternite VIII (E).

que el II; III y IV iguales; maza elíptica, alargada, más larga que los tres desmómeros precedentes reunidos.

Cabeza robusta y ancha en la base, rostro más ancho que largo $(\mathrm{L} / \mathrm{A}=0,84)$, pterigios cortos, apenas salientes; prorrostro sin puntear, bien delimitado, quilla epistomal apenas marcada, metarrostro con lados algo convergentes hacia delante; foseta frontal romboidal, profunda, algo prolongada por delante y por detrás. Ojos ovales grandes $(\mathrm{L} / \mathrm{A}=$ $1,3)$, muy poco prominentes $(21 \%)$, próximos al canto de la frente. Tegumento con algunas escamitas y microrreticulación isodiamétrica bien marcada, puntos superficiales separados, más densos en el vértice.

Pronoto grande, transversal $(\mathrm{L} / \mathrm{A}=0,3)$ moderadamente convexo, de lados bastante curvados, máxima anchura a la mitad; base finamente rebordeada, más ancha que el borde anterior. Superficie alutácea (microrreticulación) o brillante (medio y parte anterior), con puntos gruesos profundos y próximos (separados un diámetro o menos entre sí), y algunos muy pequeños en los intervalos; línea media más o menos amplia en el disco, a modo de gránulo lustroso; escamitas escasas, más concentradas hacia los márgenes. liso.

Escudete amplio, triangular, completamente

Élitros ovales, estrechos, poco acuminados (L/A $=1,5), 3 \mathrm{x}$ la longitud del pronoto y $1,7 \mathrm{x}$ su anchura; base recta, nunca cóncava; lados uniformemente curvados, la máxima anchura hacia la mitad o algo pasada; ángulo humeral redondeado, hombros brevísimos, con pequeño callo humeral. Estrías bien marcadas por puntos gruesos y profundos, algo menores que los del pronoto; interestrías por lo común poco o nada convexas, a lo ancho con 57 escamitas adpresas y separadas, quedando áreas libres de ellas que se ven oscuras. Tegumento brillante, con algunas setas negras suberectas, algo más destacadas en el ápice, pero poco desarrolladas en general 
Patas robustas, tibias rectas, todas con mucrón muy pequeño; protibias con ángulo apical externo romo, apenas curvadas hacia dentro en el ápice.

Cara ventral brillante; saliente intermesocoxal careniforme, estrecho, poco elevado; esternitos abdominales finamente bordeados, con pilosidad fina, muy abierta, más larga en los márgenes y ápice. Tegumento en metasterno y ventritos $1^{\circ}-2^{\circ}$ con microestrías transversales (casi lampiños), $3^{\circ}$ $5^{\circ}$ con microrreticulación isodiamétrica precisa y punteado superficial; el último convexamente truncado.

Edeago (Figs. 13C-D) bastante recto, temones y lóbulo medio de longitud equivalente; punta roma (aguzándose progresivamente, en vista dorsal), sin placa apical diferenciada; el saco interno rebasa hacia atrás los temones, dos campos paralelos de dentículos en el tramo medio, prácticamente unidos a los dos (más reducidos) del divertículo ciego.

Hembras. Longitud 5,6-6,5 mm. Notablemente más rechoncha, y globosa que el macho; menos brillante (tegumento elitral alutáceo, con microrreticulación); élitros inflados de lados más paralelos, con la máxima anchura hacia el tercio basal, algo más acuminados en el ápice, los hombros algo más amplios, pero igualmente caídos (ángulo humeral redondeado); disco plano, interestría sutural a veces algo deprimida; interestrías impares ligeramente tumefactas hacia los márgenes de la mitad apical; las setas negras bastante más largas y notorias (doble de largo que una uña, o más), reducidas solo en la mitad basal. Tibias inermes. Último esternito abdominal no truncado apicalmente. Gonostilo, espermateca y urosternito VIII como en las figuras $13 \mathrm{~A}, \mathrm{~B}$ y E

Etimología. El nombre específico de cephalotes está inspirado en la palabra griega "cephalos" = cabeza, para aludir a la robustez de esta pieza en comparación con la de sus vicariantes en las otras islas. Es un sustativo en aposición.

OBSERVACIONES. Laparocerus cephalotes n. $\mathrm{sp}$. pertenece al grupo de L. subtriangularis Wollaston, 1864, que ha radiado en las Canarias occidentales dando lugar varios endemismos monoinsulares. El acentuado dimorfismo sexual y la presencia de setas largas aisladas en los élitros (más desarrolladas en las $\bigcirc$ Q ) lo relaciona con L. junonius Machado, 2007 de La Gomera, L. elongatus Machado, 2009 de La Palma, y el propio L. subtriangularis y L. debilis Wollaston, 1864, ambos de Tenerife. Se distingue fácilmente de todas estas especies por la robustez de la cabeza, con la base más ancha y el morro menos estilizado, y, sobre todo, por los élitros poco acuminados en el ápice y los hombros poco marcados (ángulo humeral ampliamente redondeado y carena humeral muy breve). Esta diferencia es aún más notoria en las hembras, pues mantiene los hombros redondeados a pesar de que la base elitral se infla y la máxima anchura del élitros se desplaza hacia el primer tercio, mientras que en las hembras de las otras especies los hombros están muy desarrollados, incluso avanzados (base cóncava) y los élitros adquieren un aspecto más o menos triangular. El punteado del pronoto, profundo y denso, casi varioloso, sirve también para diferenciar los machos de L. junonius o de L. debilis, que son los más parecidos. Además, los ojos son muy poco prominentes, y la máxima anchura cefálica se produce a nivel del cuello, no de los ojos.

Unos ejemplares $0^{x} O^{x}$ de Valverde son de un tamaño mayor (longitud 6,2-6,5 $\mathrm{mm}$ ), y presentan las interestrías elitrales más convexas de lo normal.

DisTRIBUCIÓN Y ECOLOGÍA. Laparocerus cephalotes n. sp. es endémico de El Hierro y está ampliamente distribuido por toda la isla, salvo las zonas muy secas. No es muy común ni se trata de una especie arbórea, por lo que suele estar ausente en pinares y laurisilva, salvo que existan plantas bajas en las rocallas o bordes de camino. Se ha colectado preferentemente sobre Rumex lunaria (Polygonaceae), Rubia fruticosa (Rubiaceae) y, en muros de piedra húmedos, sobre Aeonium hierrense (Crassulaceae), Sonchus sp. (Asteracea) y Davallia canariensis (Davalliaceae). Suele aparecer ocasionalmente en los amasijos de vegetación ruderal (Rubus, Smilax, etc.). Es un insecto nocturno propio del otoño tardío e invierno.

\section{Laparocerus orone hierrensis $\mathbf{n}$. ssp.}

(Figs. 11C y 14A-C)

Material eXAminado. Holotipo: El Hierro: Tamaduste, $50 \mathrm{~m}$ (UTM 28R 021499 308075), $10^{\pi}$ 6-12-1999, leg. A. Machado (TFMC/CO-15956)._- Paratipos: misma localidad y datos, 39 exx +30 exx inmaturos (AMC, MNHN), 10 exx leg. R. García (RGB); La Caleta, s. Aeropuerto 180 m, 1 ex 23-2-2005; supra Puerto de la Estaca, 200 m, 3 exx 23-2-2005 leg. A. Machado (AMC).- No paratipos: Punta Ajones, túnel 10 m, 6 exx 6-121999, Guarazoca 400 m, 1 ex 23-3-2005 leg. A. Machado (AMC). Valverde N, 565 m, 15 exx 13-2-2004 leg. A. Machado (AMC), Umg. Valverde, 24 exx (nrs. 1854, 1715, 1804, etc); El Golfo 1 ex (nr. 1796), leg. H. Franz (NMW); Cruz del Calvario, 5 exx 6-12-2008 leg. R. García (RGB). 


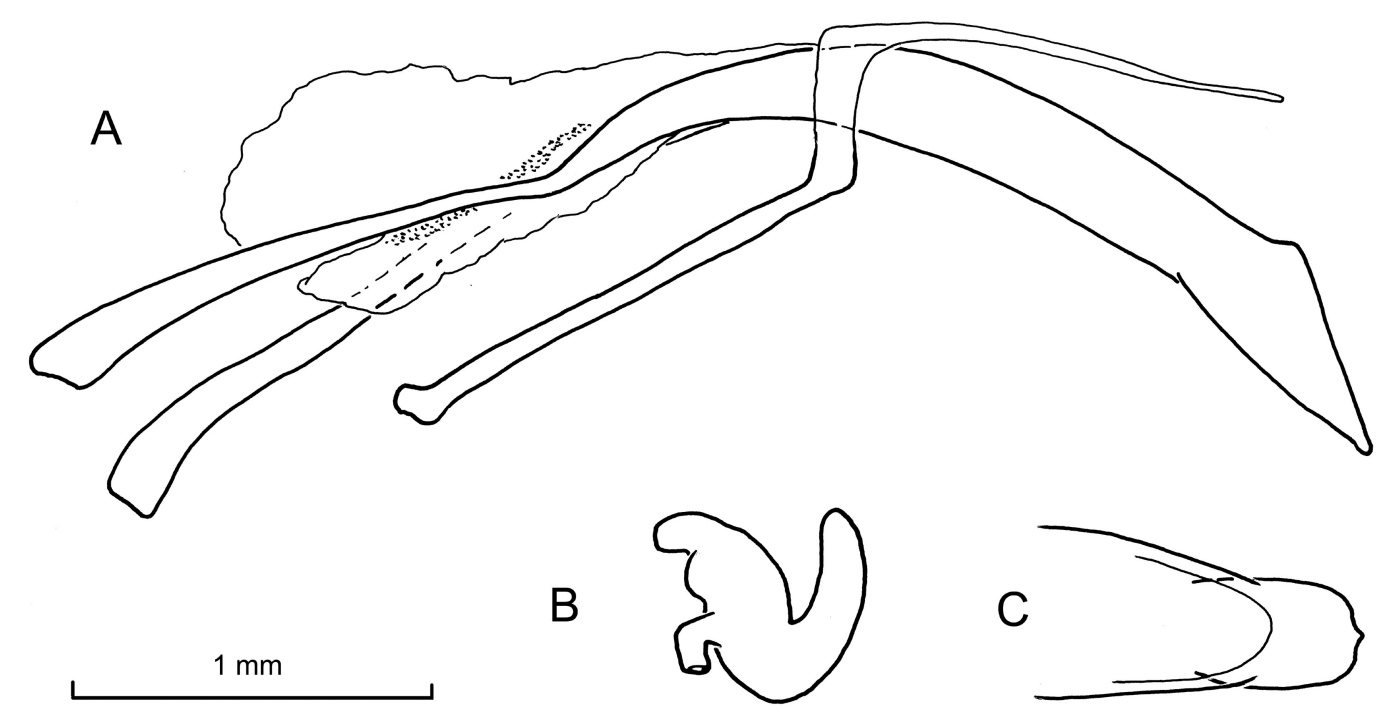

Fig. 14.- Laparocerus orone hierrensis n. ssp. Edeago (A), espermateca (B) y ápice del lóbulo medio del edeago en vista dorsal (C).

Fig. 14.- Laparocerus orone hierrensis n. ssp. Aedeagus (A), spermatheca (B) and median lobe apex in dorsal view (C).

[¿Otra subespecie?] Sendero Jinama $(\mathrm{Km} \mathrm{0,5),} 1$ ex 12-22004, Tiñor 920 m, 3 exx 22-2-2005, Tiñor Km 3, 780 m 1 ex 22-2-2005; Ermita de los Reyes 720 m, 7 exx 11-2-2004 leg. A. Machado (AMC); Camino Jinama 4-12-2008 leg. R. García (RGB).

Medidas del holotipo $\left(\sigma^{t}\right)$. Longitud: total ( $\sin$ rostro) $4,60 \mathrm{~mm}$, cabeza $1,04 \mathrm{~mm}$, rostro $0,52 \mathrm{~mm}$, escapo $1.04 \mathrm{~mm}$, funículo 1,14 (desmómeros 1-4 respectivamente $0,26 / 0,30 / 0,19 / 0,17 \mathrm{~mm}$ ), clava $0,46 \mathrm{~mm}$, pronoto $0,94 \mathrm{~mm}$, élitros $3,35 \mathrm{~mm}$, tibias (pro- /meso- /meta-) 1,20/1,10/1,32 mm. Anchura: cabeza (a nivel de los ojos) 0,94 mm, frente 0,60 $\mathrm{mm}$, rostro (a nivel de los pterigios) $0,60 \mathrm{~mm}$, rostro (mínimo dorsal /ventral) $0,37 / 54 \mathrm{~mm}$, rostro (base) $0,62 \mathrm{~mm}$, escapo $0,14 \mathrm{~mm}$, clava $0,13 \mathrm{~mm}$, pronoto (anterior /máxima /posterior) 0,92/1,28/ $1,12 \mathrm{~mm}$ y élitros (máxima) $2,10 \mathrm{~mm}$. Altura: abdomen $1,55 \mathrm{~mm}$.

DiAgNOSIS DIFERENCIAL. Longitudes $\sigma^{7} \sigma^{7} 3,8$ $5,0 \mathrm{~mm}$, 우 우 4,5-5,2 $\mathrm{mm}$. Igual que Laparocerus orone orone Machado, 2009, pero de aspecto más estilizado y elíptico, particularmente las hembras, que son menos robustas (hombros más caídos) y apenas un poco más anchas que los machos. Pronoto con punteado menos agregado, puntos mayores más precisos y separados, los menores muy superficiales; área media parcialmente despe- jada, brillante. Élitros lateralmente más curvados, máxima anchura en la mitad; puntos de las estrías no mayores en machos que en hembras, prácticamente iguales. Edeago y espermateca sin diferencias notorias (Fig. 14).

ETimología. El epíteto subespecífico es un adjetivo que hace referencia a la isla de El Hierro, de donde la subespecie es endémica.

OBSERVACIONES. Laparocerus orone s. 1. ha diferenciado poblaciones en La Gomera (ssp. orone Machado 2007), La Palma (ssp. aridane Machado 2009) y El Hierro. La punta del lóbulo medio del edeago (Fig. 14) es muy característica en esta especie y permite separarla fácilmente de las dos especies más próximas y parecidas, que habitan en $\mathrm{La}$ Gomera: L. acutipennis Machado 2007 y L. benchijigua Machado 2007. Además, estas dos especies presentan setas negras erectas en los élitros y L. orone s. 1. no.

Los ejemplares procedentes de zonas altas $(600-$ $1000 \mathrm{~m}$ ) y más húmedas de la isla de El Hierro se diferencian morfológicamente de los procedentes de zonas bajas $(<400 \mathrm{~m})$, más xéricas. Su talla es mayor (5,1-6,4 mm), los ojos son algo más pequeños (distancia interocular /diámetro mayor $=2,9$ frente a 2,1) y los élitros son notoriamente más 
alargados con una proporción longitud élitro /pronoto de 4,0 de media (ambos sexos), mientras que en la serie típica es 3,5. Es posible que existan dos subpoblaciones diferenciadas dentro de la isla, aunque no se aprecia diferencia alguna en el edeago, y las ratio élitro/pronoto obtenidas de series colectadas a altitudes intermedias, también dan resultados intermedios (3,8 Ermita de los Reyes a $720 \mathrm{~m}$ y 3,9 Valverde aprox. $600 \mathrm{~m}$ ). Bien podría tratarse de una morfoclina debida a factores ecológicos; a la humedad, en concreto. Para resolver esta duda es preciso contar con más material, particularmente de localidades intermedias.

DISTRIBUCIÓN Y ECOLOGÍA. Laparocerus orone hierrensis $\mathrm{n}$. ssp. es endémico de la isla de El Hierro. Se distribuye por la zona xérica con vegetación subsuculenta, así como por los campos abiertos en zona de montaña y clima más húmedo, pero eludiendo las áreas boscosas. Es nocturno y se alimenta al menos de Artemisia thuscula, Argyranthemum frutescens s.l., Schyzogyne sericea (Asteraceae), Cistus monspeliensis (Cistaceae) y ocasionalmente de Erysimum bicolor (Apiaceae).

\section{Laparocerus hypogeus $\mathbf{n}$. sp.}

(Figs. 15A y 16A-B)

Material examinado. Holotipo: El Hierro, Frontera, Pista del Derrabado 790 m (UTM 27R 0790169 3072011), 1 우 (nr. 5435) 15-1-2010, leg. GIET (ULL). Único ejemplar conocido.

Medidas DEL HOLOTIPO ( ). Longitud: total ( $\sin$ rostro) $6,9 \mathrm{~mm}$, rostro $0,85 \mathrm{~mm}$, escapo $1,64 \mathrm{~mm}$, funículo 1,55 (desmómeros I-IV respectivamente 0,42 / 0,31 / 0,18/0,18 mm), maza 0,70 mm, ojo $0,17 \mathrm{~mm}$, pronoto $1,55 \mathrm{~mm}$, élitros $4,90 \mathrm{~mm}$, tibias (pro- /meso- /meta-) 1,68/1,62/2,05 mm. Anchura: cabeza (a nivel de los ojos) $0,90 \mathrm{~mm}$, (interocular) $0,80 \mathrm{~mm}$; rostro (a nivel de los pterigios) $0,80 \mathrm{~mm}$, (dorsal al medio) 0,68 mm, (mínimo dorsal) 0,46 $\mathrm{mm}$ (mínimo ventral) $0,24 \mathrm{~mm}$; maza $0,20 \mathrm{~mm}$, ojo $0,12 \mathrm{~mm}$, pronoto (anterior /máxima /posterior) $1,23 / 1,77 / 1,57 \mathrm{~mm}$ y élitros (máxima) 3,05 mm. Altura: abdomen $2,20 \mathrm{~mm}$. Le falta la pata intermedia izquierda, guardada para extraerle el ADN.

DESCRIPCIÓN. Hembra: Longitud: 6,9 mm. Laparocerus de tamaño mediocre y aspecto fusiforme. Tegumento bien pigmentado, brillante, de color pardo oscuro, con los tarsos y flagelo antenal rojizos y claros. Aspecto glabro, con pelitos diminutos visibles solo a gran aumento.
Antenas recias; escapo largamente capitado, comprimido dorsoventralmente, prácticamente rectilíneo; desmómero I algo mayor que II; maza elíptica $(\mathrm{L} / \mathrm{A}=3,5)$, grande, algo mayor que los cuatro desmómeros precedentes.

Cabeza de base ancha y cónica; rostro de aspecto largo $(\mathrm{L} / \mathrm{A}=1,1)$ y paralelo; pterigios auriculariformes muy salientes; prorrostro bien demarcado, deprimido al medio, estrechado hacia el ápice; quilla epistomal mal definida; prorrostro acanalado, márgenes llamativamente tumefactos, fuertemente punteados, y algo convexos (máxima anchura a la mitad); canal central con surcado longitudinal; frente brusca y brevemente deprimida de lado a lado, demarcado la base del rostro; foseta corta, longitudinal, algo prolongada hacia delante. Tegumento densamente punteado, con algunas escamitas piliformes diminutas en rostro y genas. Sección del rostro en trapecio invertido (más ancho dorsal que ventralmente), cara ventral estrecha, submentón subparalelo, ancho, deprimido y puntado. Escrobas bien demarcadas bajo alero formado por margen prorrostral engrosado. Ojos próximos pero separados del canto lateral de la frente, reducidos a un óvalo cuasi-plano con una veintena de omatidios.

Pronoto poco más ancho que largo $(\mathrm{L} / \mathrm{A}=0,9)$, máxima anchura a la mitad, lados poco curvados, base claramente rebordeada. Tegumento brillante, con doble punteado bien desarrollado; puntos gruesos mediocres, bastante separados entre sí; pelitos suberectos, inconspicuos, visibles de perfil. Disco con superficie algo irregular anterior y lateralmente, sin línea media.

Escudete triangular, ancho, corto y glabro.

Élitros oblongo-alargados, poco convexos, uniformemente arqueados lateralmente; base ligeramente cóncava, con hombres muy cortos, apenas marcados; ápice con declive pronunciado y brusco (máxima elevación hacia el quinto apical); estrías punteadas bien marcadas; interestrías moderadamente convexas, la 7A algo carinada en la base, la 8A parcialmente visible desde arriba en la mitad basal. Tegumento liso, brillante, con marcas transversales irregulares, separadas y puntos superficiales irregulares (portan pelitos diminutos, lo mismo que los puntos de las estrías). Unas pocas escamas setiformes más largas, en el mismo ápice y borde apical.

Patas cortas, recias. Tibias inermes (sin mucro), comprimidas lateralmente y notoriamente punteadas; protibias subrectas, poco escotadas interna- 

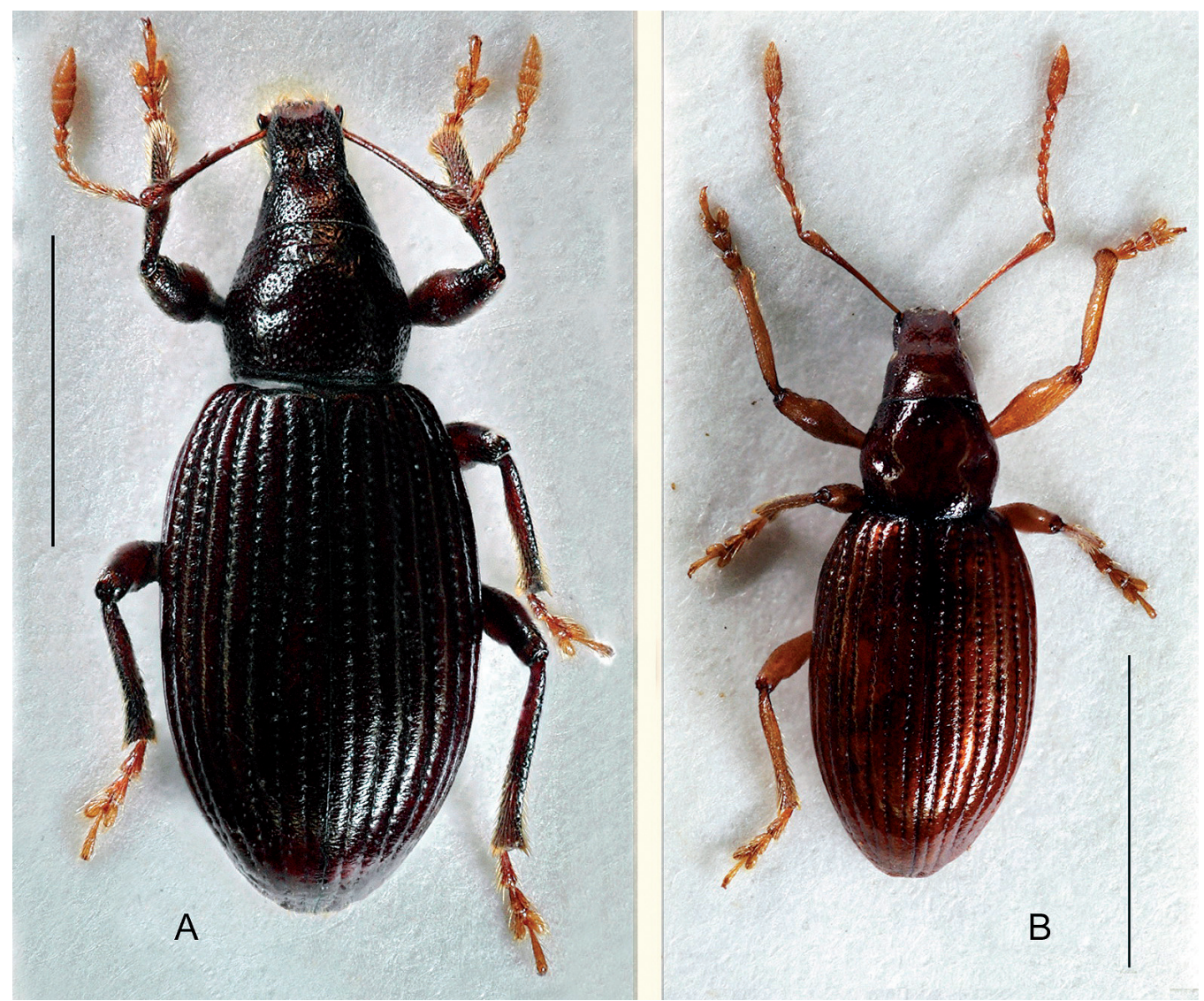

Fig. 15.- Holotipo $0^{\prime \prime}$ de Laparocerus hypogeus n. sp. (A) y holotipo $0^{\prime \prime}$ de Laparocerus cavernarius n. sp. (B). Escala $=3$ $\mathrm{mm}$.

Fig. 15.- Holotype $\sigma^{\pi}$ of Laparocerus hypogeus n. sp. (A) and holotype $\sigma^{\pi}$ of Laparocerus cavernarius $\mathbf{n} . \mathbf{s p}$. (B). Scale $=3 \mathrm{~mm}$.

mente; ángulo apical externo romo, el interno agudo, algo expandido. Tarsos gráciles.

Cara ventral brillante, tegumento punteado, con microestriado transversal en ventritos 1-2; pilosidad abierta, moderadamente desarrollada. Saliente prosternal cariniforme, estrecho, poco desarrollado. Útimo ventrito subtruncado apicalmente.

Genitalia: Gonocoxitos muy cortos, con seis setas (Fig. 16A). Esternito VIII (Fig. 16B) corto, con placa apical roma, provista de setas largas. La espermateca se encontraba contrahecha y destrozada, tal vez por efecto del líquido conservador de las trampas empleadas para la captura (propilenglicol).

ETIMOLOGíA. El nombre específico de hypogeus es un adjetivo que hace mención a los hábitos subterráneos de la especie.
OBSERVACIONES. Laparocerus hypogeus n. sp. se caracteriza por sus ojos reducidos, el pronoto rebordeado en la base, el punteado fuerte en el pronoto, cabeza y tibias, y por el rostro más ancho dorsal que ventralmente, con los márgenes fuertemente tumefactos haciendo de visera sobre la escroba.

DistRiBUCión Y ECOLOGÍA. El único ejemplar que se conoce de esta especie es una hembra capturada en una trampa colocada en el medio subterráneo superficial (MSS) en zona de laurisilva, en las laderas del valle de El Golfo, en la isla de El Hierro. Se trata probablemente de un endemismo local restringido al subsuelo de la zona forestada y húmeda de la vertiente septentrional de la isla. 


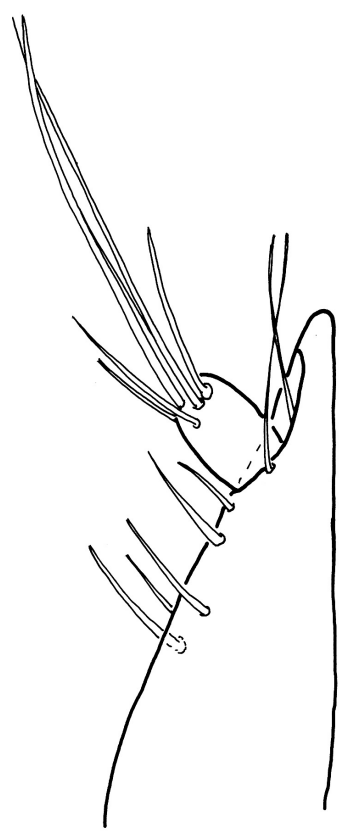

A

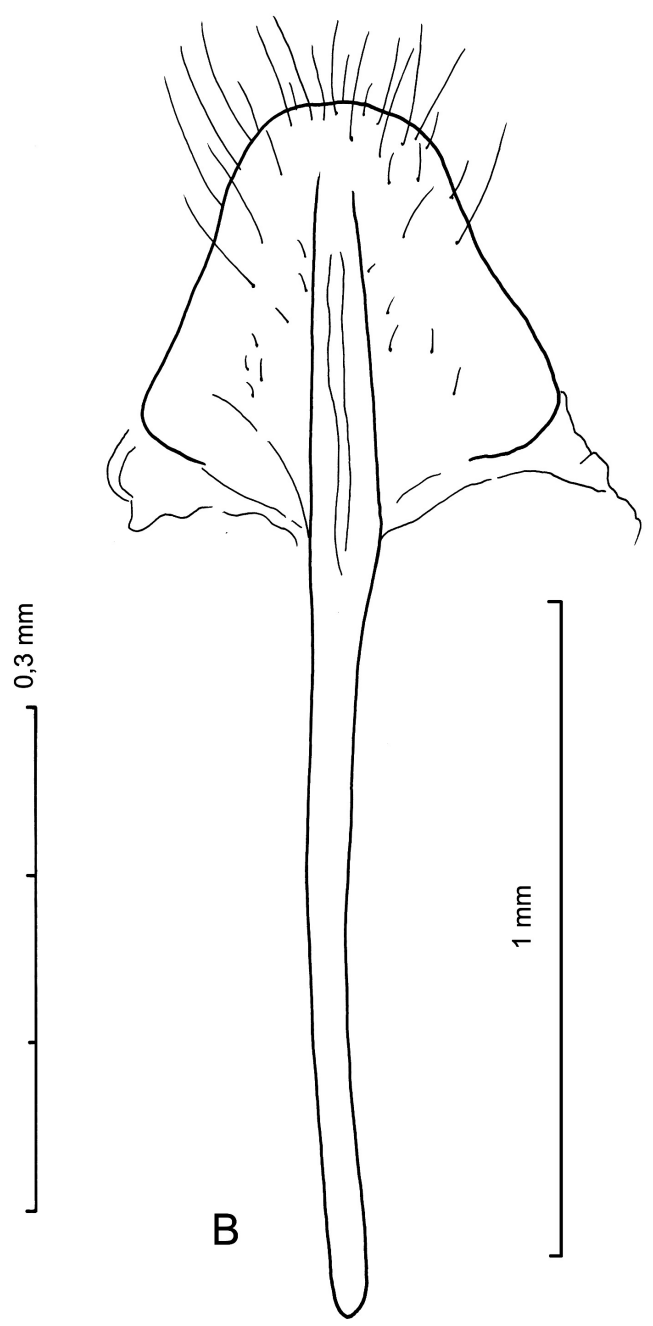

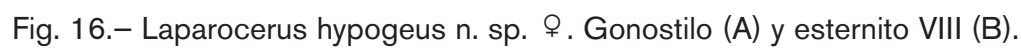

Fig. 16.- Laparocerus hypogeus n. sp. $\odot$. Gonostyle (A) and sternite VIII (B).

\section{Laparocerus cavernarius $\mathbf{n} . \mathbf{s p}$.}

(Figs.15B y 17A-C)

Material examinado. Holotipo: El Hierro, El Pinar, Cueva de la Curva, 620 m (UTM 28R 0206798 3066660), $10^{7}$ (CV-B13/CO 4390) 16-10-2010, leg. GIET (ULL).Paratipos: Misma localidad, $10^{\pi}$ (inmaturo con élitro derecho deforme) 13-2-2004 leg. Morales (AMC), 1 ㅇ (encontrada muerta, cabeza, tórax y abdomen, y una pata suelta, 14-2-2004 leg. H. López (ULL).

Medidas DEL HOLOTIPO $\left(\sigma^{T}\right)$. Longitud: total ( $\sin$ rostro) $5,00 \mathrm{~mm}$, rostro $0,60 \mathrm{~mm}$, escapo $1,20 \mathrm{~mm}$, funículo 1,24 (desmómeros I-IV respectivamente $0,30 / 0,28 / 0,14 / 0,14 \mathrm{~mm})$, maza $0,58 \mathrm{~mm}$, ojo
$0,14 \mathrm{~mm}$, pronoto $1,11 \mathrm{~mm}$, élitros $3,40 \mathrm{~mm}$, tibias (pro- /meso- /meta-) 1,30/1,20/1,50 mm. Anchura: cabeza (a nivel de los ojos) 0,74 mm, (interocular) $0,58 \mathrm{~mm}$; rostro (a nivel de los pterigios) $0,60 \mathrm{~mm}$, (mínimo dorsal) 0,40 mm (mínimo ventral) 0,60 $\mathrm{mm}$; maza $0,15 \mathrm{~mm}$, ojo $0,10 \mathrm{~mm}$, pronoto (anterior /máxima /posterior) $0,96 / 1,26 / 1,16 \mathrm{~mm}$ y élitros (máxima) 2,13 mm. Altura: abdomen 1,70 mm. Le falta la pata posterior derecha, guardada para extraerle el ADN.

DESCRIPCIÓN. Macho: Laparocerus de tamaño mediocre (longitud $=5 \mathrm{~mm}$ ), oblongo estrecho. 


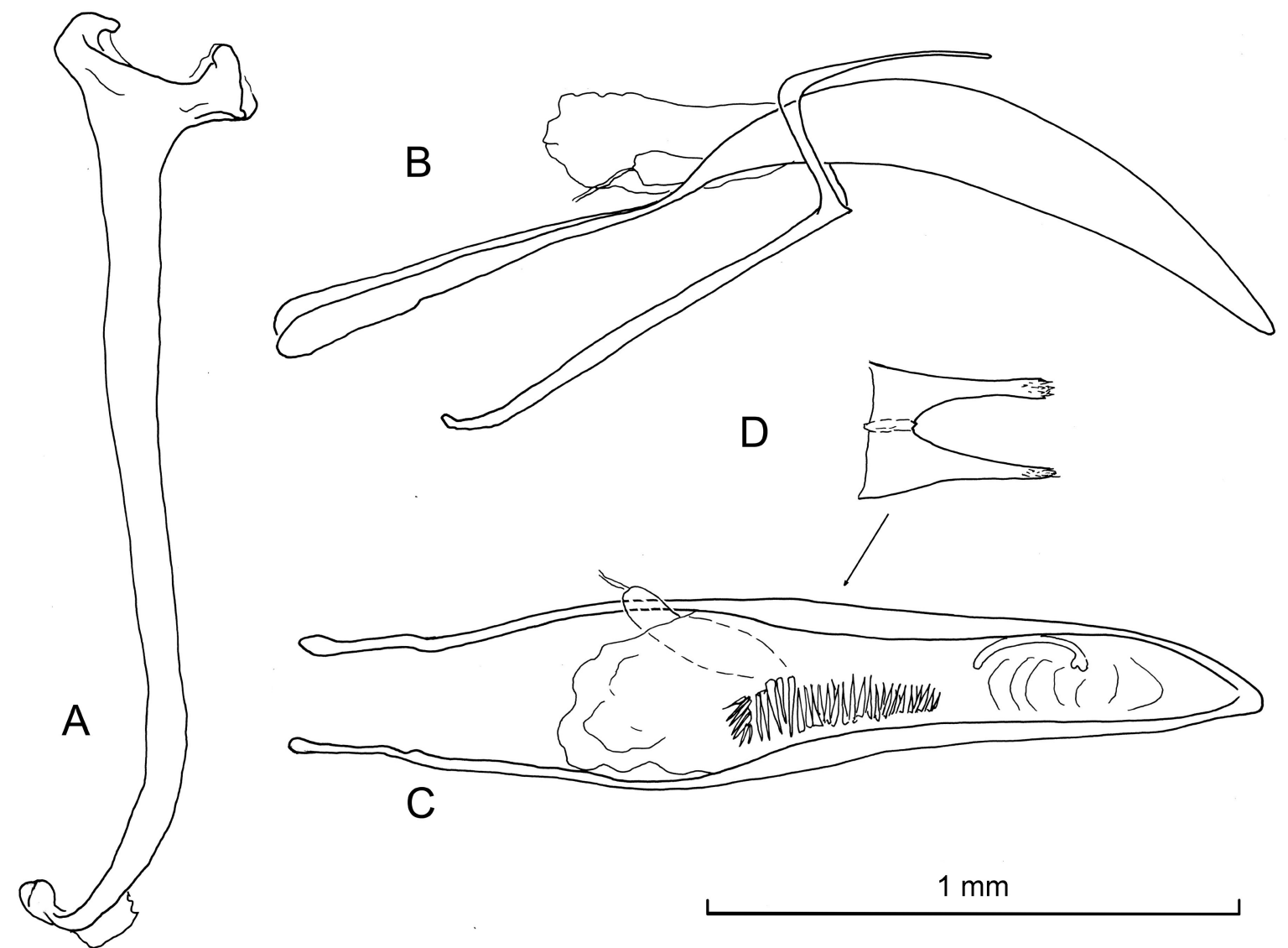

Fig. 17.- Laparocerus cavernarius n. sp. $\sigma^{7}$. Espículo gastral (A), edeago en vista lateral (B), lóbulo medio en vista dorsal (C) y detalle de los parámeros del tegmen (D).

Fig. 17.- Laparocerus cavernarius n. sp. $0^{7}$. Spiculum gastrale (A), aedeagus in lateral view (B), median lobe in dorsal view (C), and detail of the tegmen parameres (D).

Tegumento de aspecto glabro, bastante despigmentado, muy brillante y color caramelo rojizo.

Antenas recias; escapo cilíndrico, capitado, apenas sinuoso, prácticamente tan largo como el pronoto; desmómero I y II casi iguales; maza elíptica alargada $(\mathrm{L} / \mathrm{A}=3,9)$, mayor que los cuatro desmómeros precedentes.

Cabeza robusta, de base ancha con lados moderadamente convergentes, sienes y vértex convexos; rostro tan largo como ancho $(\mathrm{L} / \mathrm{A}=1,1)$, progresiva y uniformemente convergente hacia delante, de sección trapezoide; pregenas desarrolladas, visibles desde arriba; pterigios cortos, apenas salientes; prorrostro deprimido al medio; quilla epistomal apenas definida; prorrostro suavemente deprimido a lo largo, márgenes apenas levantados; frente ligeramente deprimida de lado a lado; foseta corta, algo prolongada hacia delante. Tegumento brillante, poco y superficialmente punteado, con muy pocas escamitas piliformes microscópicas; vértex casi liso. Ojos planos, próximos pero separados del canto lateral de la frente, reducidos a una treintena de omatidios.

Pronoto más ancho que largo $(\mathrm{L} / \mathrm{A}=0,85)$, lados curvados, máxima anchura hacia la mitad; base sin rebordear. Disco con dos fóveas amplias oblicuas a cada lado rebasada la mitad. Tegumento lustroso con puntos muy superficiales y separados, poco aparentes; marcados solo en los flancos ventrales. 
Escudete triangular, ancho, corto y glabro.

Élitros oblongo ovalados, poco convexos, subparalelos en su tramo medio; base sin hombros; ápice con declive pronunciado; estrías punteadas con puntos mediocres; interestrías subconvexas, la $8^{\mathrm{a}}$ algo visible desde arriba en la mitad basal. Estría $5^{\mathrm{a}}$ sinuosa ( $6^{\mathrm{a}}$ interestría ensanchada parcialmente) y convergente sobre la $6^{\mathrm{a}}$ en la base. Tegumento liso, brillante, con marcas transversales irregulares separadas y poco marcadas; micropuntos visibles, con pelito microscópico difícil de apreciar; alguna escama setiforme en el mismo ápice.

Patas cortas, poco pilosas. Tibias con mucrón pequeño (el metatibial diminuto); protibias moderadamente escotadas por dentro en la mitad distal; ángulo apical externo ampliamente curvado, el interno agudo, algo expandido. Tarsos gráciles.

Cara ventral brillante, tegumento, con microestrías transversales en ventritos 1-2; pilosidad rubia corta y abierta. Saliente prosternal cariniforme, apenas desarrollado. Último ventrito ampliamente truncado apicalmente y ligeramente escotado al medio.

Edeago corto (Figs. 17B-C), lóbulo muy poco arqueado, aguzado apicalmente, con la punta simple y roma; temones cortos, engrosados apicalmente y muy delgados en la base; parámeros del tegmen con flecos apicales; saco interno muy corto (en posición de reposo no rebasa los temones), con un campo mediano de densos dentículos; el divertículo gonoporal corto en posición dorsolateral; el divertículo ciego inerme. Espículo gastral muy robusto (Fig. 17A).

Hembra: Mayor que el macho (7,9-9,8 mm), con la escultura cefálica más pronunciada (prorrostro más acanalado y márgenes algo inflados); pregenas bastante más abultadas; élitros algo más inflados, de lados más subparalelos, con los puntos de las estrías menores y las interestrías planas. Tibias inermes. Margen apical del ventrito V subtruncado, no escotado al medio.

Etimología. El nombre específico de cavernarius es un adjetivo derivado de caverna, en alusión a la cueva formada por un tubo volcánico, donde fue hallada la especie.

OBSERVACIONES. Laparocerus cavernarius n. $\mathrm{sp}$. se distingue fácilmente de los demás Laparocerus de hábitos hipogeos y con ojos reducidos, por la presencia de una fóvea oblicua a cada lado del pronoto. De la otra especie presente en la isla de El Hierro, Laparocerus hypogeus n. sp., se distingue además por el tegumento brillante con punteado muy superficial, ausencia de hombros, micropilosidad aún más reducida (muy difícil de observar), el rostro más ancho ventral que dorsalmente y los márgenes del prorrostro nada o mucho menos tumefactos (hembras).

DiSTRIBUCIÓN Y ECOLOGÍA. Laparocerus cavernarius $\mathrm{n}$. ssp. es endémico de la isla de El Hierro y se ha encontrado solo en una cueva volcánica de dos niveles asociada a un cono de cínder (a $620 \mathrm{~m}$ de altitud), en hábitat de tabaibal, con Euphorbia regis-jubae (Euphorbiaceae) y Rumex lunaria (Polygonacea). La especie no se ha encontrado en otras cuevas próximas situadas a menor altitud en la misma vertiente meridional de la isla. En la vertiente septentrional habita la especie anterior, en ambiente mucho más húmedo.

\section{Comentarios sobre otras especies}

Franz (1996) publica un trabajo sobre la fauna coleopterológica de El Hierro basado en sus colectas a lo largo de 26 años, en el que aparecen numerosas citas de especies cuya presencia en la isla es altamente improbable (v. Machado 1992). Se trata aparentemente de errores de etiquetado o de ejemplares trasportados desde otras islas con los instrumentos de colecta (tamices, sacos de transporte, aparatos de Winkler, etc.). Estos problemas parecen afectar a los Laparocerus reunidos por Franz y, para colmo, tampoco existe una correlación exacta entre lo que cita en su trabajo (op. cit.) y el material contenido en su colección, depositada en el Museo de Historia Natural de Viena. El autor austriaco escribió su último trabajo sobre Canarias a edad muy avanzada y todo parece indicar que no manejó sus fichas y registros con mucha precisión. Siguen, pues, las citas de Franz a excluir de la fauna herreña, y otras citas que merecen comentario.

Laparocerus gracilis Wollaston, 1865. Citado por Franz (1996) para San Andrés, en prados, obtenidos en abundancia tamizando excrementos de burro (18-2-1992), más un ejemplar (4-1-1993) de La Dehesa. En la colección Franz no existe material esta especie endémica de la Gomera, que vive sobre Periploca laevigata (Asclepiadaceae). Todo parece indicar que la ha confundido con Laparocerus puncticollis Wollaston 1864. 
Laparocerus gomerensis Lindberg, 1953. Franz (1996) cita esta especie para el Hierro, concretamente de las localidades de La Dehesa, por encima del bosquete de sabinas (1 ex muerto 16-2-1980); El Golfo, camino a la fuente de Tinco (31-1-1980 y 132-1991), El Golfo, mantillo de laurisilva 23/26-31968). No he encontrado estos ejemplares en su colección ni existe tampoco material de La Gomera. Hay una serie de 24 exx de L. orone hierrensis n. sp., no referenciados en su trabajo y que Franz podría haber confundido con esta especie (o la anterior), pero figuran como colectados en los alrededores de Valverde. He batido las cumbres de El Hierro y alguno de los pocos ejemplares de Adenocarpus umbriosus (Fabaceae) que se conocen, sin éxito alguno. De momento, es aconsejable anular estas citas, aunque no se puede descartar del todo la presencia de un representante del grupo de L. scapularis Wollaston, 1864 en la Isla, pues cuenta con vicariantes en La Gomera, Tenerife y La Palma.

Laparocerus obscurus Wollaston, 1864. Los ejemplares determinados por Franz (1996) como $L$. obscurus -especie endémica de Tenerife- son $L$. incomptus (Wollaston, 1865), endémica de El Hierro y antes considerada sinónima de L. tibialis (v. Machado, 2006). Respecto de esta última especie, Franz incluye en su trabajo solo la referencia de Wollaston (1865) a los ejemplares colectados por Crotch, pues no hay citas adicionales posteriores. Este equívoco en concreto confirma que el autor austriaco no conocía bien el género Laparocerus.

Laparocerus inermis Machado, 2007. En la Colección Franz existen doce ejemplares etiquetados como de "El Hierro, alrededores de Valverde", que pertenecen a este endemismo de La Gomera, y coinciden con la morfología algo peculiar, asociada a la localidad de la Degollada de Hermua, entre el barranco de Benchijigua y el de las Toreas. He batido los alrededores de Valverde en numerosas ocasiones sin hallar rastro de la especie, lo que me reafirma en la convicción de que se trata de un error de etiquetado. Por otra parte, Franz (1996) cita 4 ejemplares de $L$. occidentalis Wollaston 1864, inexistentes en su colección, que por su tamaño podrían confundirse con $L$. inermis, y en este caso al menos uno coincide en localidad (Valverde, praderas cerca del campo de fútbol).

Laparocerus (Fernandezius) impressicollis Wollaston, 1864. Citado por Roudier (1957) sobre un único ejemplar supuestamente colectado por Joaquín Mateu en El Golfo. La especie se conoce de Tenerife y La Palma, y nunca más ha vuelto a ser encontrada en El Hierro. Suponemos que se trata igualmente de un transporte fortuito entre los instrumentos de colecta. A excluir de la fauna herreña.

Laparocerus ellipticus Wollaston, 1863. Esta especie se conocía de las islas de Gran Canaria, Tenerife, La Palma y La Gomera, y ahora se completa su distribución a todas las Canarias occidentales con la confirmación de su presencia en El Hierro. El Dr Oromí y otros miembros del GIET encontraron el 15-2-2004 seis ejemplares en plena laurisilva, en la Pista del Derrabado que recorre parte de la ladera occidental del Valle de El Golfo.

\section{Agradecimientos}

El autor expresa su agradecimiento a los Drs. Pedro Oromí y Heriberto López (Grupo de Investigaciones Espeleológicas de Tenerife-GIET, Universidad de La Laguna) que aportaron dos especies nuevas para ser descritas en este trabajo, así como a los demás colegas que permitieron estudiar el material de sus colecciones privadas. El Dr. Heinrich Schönmann facilitó el acceso al estudio de la Colección Franz en el Naturhistorisches Museum Wien, la Dra. Hélène Perrin a la Colección Roudier en el Museum d'Histoire Naturelle (París), y el Dr Max Barclay, a la Colección Wollaston en el Natural History Museum (Londres). El Dr Michael Morris revisó la versión inglesa de las claves.

\section{Referencias}

Franz, H., 1996. Die Ergebnisse meiner langjährigen Aufsammlungen der Coleopterenfauna auf der Insel Hierro (Kanarische Inseln). Sitzungsberichte der mathematisch-naturwissenschaftlichen Classe der Kaiserlichen Akademie der Wissenschaften, Wien, [1995], 202: 71-138.

LindBERG, H. \& LindBERG, H., 1958. Entomologische Ergebnisse der finnländischen Kanaren-Expedition 1947-51. No. 14. Coleoptera Insularum Canariensium. I. Aglycyderidae und Curculionidae. Commentationes biologicae, Societas Scientiarum Fennica, 17(1): 1-97.

Machado, A., 1992. Monografía de los Carábidos de las islas Canarias (Insecta, Coleoptera). Instituto de Estudios Canarios. La Laguna. 734 pp.

Machado, A., 2005. Laparocerus bacalladoi, nueva especie de la isla de Tenerife, Canarias (Coleoptera, Curculionidae). Vieraea, 33: 539-543.

Machado, A., 2006. The type material of the species of Laparocerus Schönherr, 1834 (Coleoptera, Curculio- 


\section{Clave de las especies de Laparocerus de la isla de El Hierro}

1 Ojos rudimentarios, planos (reducidos a unos pocos omatidios)

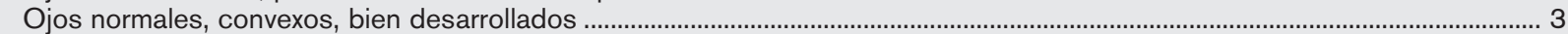

2 Pronoto con una fóvea oblicua postmediana a cada lado en el disco; tegumento brillante, liso, con punteado muy superficial

Pronoto sin fóveas discales, con punteado doble bien marcado

Laparocerus cavernarius $\mathrm{n}$. sp.

Laparocerus hypogeus n. sp.

3 Ojos emplazados a la mitad del flanco lateral de la cápsula cefálica, muy alejados del borde de la frente. Tegumento completamente tapizado por diminutas escamitas adpresas en forma de lágrima puntiaguda aplastada ............................................. 4

- Ojos emplazados tangentes muy próximos al borde lateral de la frente. Tegumento lampiño o con escamas lineares o lanceoladas más o menos densas

4 Élitros con protuberancias grandes, sobresaliendo en los márgenes laterales, provistos de setas claras y anchas ................. 5

- Élitros sin protuberancias llamativas al menos en la mitad anterior, con hileras regulares de setas muy cortas ........................ 6

5 Protuberancias menos desarrolladas; setas lanceoladas, su anchura decreciendo hacia el ápice

Laparocerus (Fernandezius) subnodosus subcalvus (Wollaston, 1864)

- Protuberancias más pronunciadas y sobresalientes; setas erectas ensanchándose hacia su ápice

Laparocerus (Fernandezius) sculptipennis (Wollaston, 1864)

6 Márgenes dorsales del rostro brevemente escotados por detrás del nivel de inserción de las antenas; pregenas no abultadas ventralmente ............................................................. Laparocerus (Fernandezius) tesserula seriesetosus (Wollaston, 1864)

- Márgenes dorsales del rostro, normales, a lo sumo algo estrangulados; pregenas muy abultadas ventralmente

Laparocerus (Mateuius) auctus auctus (Wollaston, 1864)

7 Élitros con setas o pelos largos y rectos, presentes en toda su extensión o al menos unos pocos en el tercio apical (tan lar-

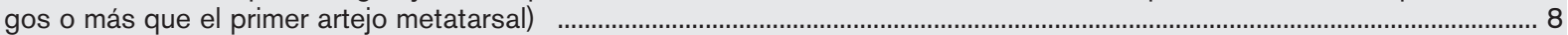

- Élitros sin pelos largos, lampiños, o con setas recias muy cortas o recurvadas ………….............................................................. 12

8 Pelos o setas largos restringidos a unos pocos en el tercio apical de los élitros ..................................................................... 9

- Pelos o setas largos repartidos por todo el élitro ................................................................................................................ 10

9 Élitros anchos y elípticos, sin hombros. Pelos apicales rectos, escasos y blanquecinos, de varios tamaños ...............................

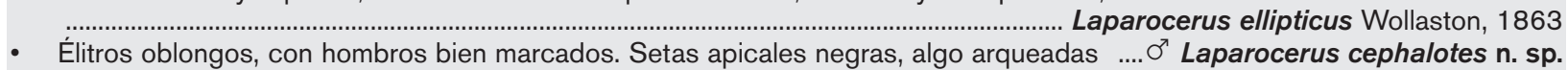

10 Protibias expandidas en el ápice hacia ambos lados (en "abanico"). Cabeza y pronoto sin o con escasa pilosidad, tumbada, poco aparente

.. 10

- Protibias con el ángulo apical externo suavemente curvo. Cabeza y pronoto con pilosidad abundante y sobresaliente (algo menor que la elitral)

11 Talla $>$ 6,5 $\mathrm{mm}$. Pronoto finamente punteado. Pilosidad elitral clara, muy fina y separada

Laparocerus sanchezi Roudier, 1957

Laparocerus lepidopterus lepidopterus Wollaston, 1864

- Talla $<6,5 \mathrm{~mm}$. Pronoto con punteado grueso y varioloso (hembras con gibosidad en la base del pronoto). Pilosidad elitral recia, negra

12 Superficie elitral normal, sin protuberancias (a lo sumo una apical)

Laparocerus (Fortunotrox) puncticollis Wollaston, 1864

- Superficie elitral con varias protuberancias muy llamativas a lo largo de las interestrias impares

Laparocerus mateui tuberosus n. sp.

13 Pronoto y élitros con vestimenta de escamas o de setas diminutas. Ápice de las protibias no expandido a ambos lados en el ápice......

- Pronoto y élitros completamente lampiños, sin escamas ni setas. Ápice de las protibias fuertemente expandido a cada lago (en abanico)

Laparocerus (Machadotrox) aethiops aethiops Wollaston, 1864

14 Escudete triangular, visible. Tegumento elitral liso, con vestimenta de escamitas lanceoladas tumbada más o menos densas y formando dibujo.

- Escudete granular en visión dorsal, dispuesto verticalmente sobre el grueso borde basal del élitro. Tegumento elitral negro con microrrugosidad transversal, provisto de hileras de diminutas setas negras recurvadas

Laparocerus (Amyntas) incomptus Wollaston, 1865

15 Talla $<8 \mathrm{~mm}$. Pronoto con tegumento brillante o lustroso, microescultura superficial, con o sin micropuntos además de los puntos mayores

- Talla $>8 \mathrm{~mm}$. Pronoto con tegumento mate, micrroreticulación poligonal muy marcada, entre los puntos menores y mayores (muy precisos)

Laparocerus occidentalis Wollaston, 1864

16 Frente plana, no particularmente deprimida (en el mismo plano que el rostro) ………...........................................................17

- Frente claramente deprimida de lado a lado ……...................................................................................................... 18

17 Máxima anchura de la cabeza a nivel de los ojos (ojos incluidos). Élitros bastante más anchos que el pronoto, provistos de setas arqueadas tumbadas de color claro (poco notorias) …………........................................... Laparocerus bimbache $\mathrm{n}$. sp.

- Máxima anchura de la cabeza a nivel del cuello. Élitros poco más anchos que el pronoto, con setas erectas negras prominentes, dirigidas hacia atrás ..................................................................................................... ㅇ Laparocerus cephalotes $\mathrm{n}$. sp.

18 Dorso del rostro subparalelo y casi tan ancho como ventralmente. Élitros redondeados apicalmente (en las hembras con una tumefacción apical), provistos de setas arqueadas muy pequeñas

Laparocerus mendicus Wollaston, 1864

- Dorso del rostro abruptamente constreñido por delante, casi la mitad de ancho que ventralmente. Élitros acuminados, con pilosidad corta y poco conspicua limitada al ápice

Laparocerus (Fortunotrox) orone hierroensis n. sp. 


\section{Key to the species of Laparocerus from El Hierro Island}

1 Eyes rudimentary, flat, reduced to a group of few ommatidia

- Eyes normal, convex, well developed

2 Pronotum at disc with a postmedian oblique fovea on each side; integument shiny, with superficial punctures .......................

Laparocerus cavernarius n. sp.

- Pronotum without discal fovea; integument with well impressed punctures (small and large) .. Laparocerus hypogeus $\mathbf{n}$. sp.

3 Eyes placed at middle of the sides of head capsule, distant from lateral border of frons. Integument completely paved with short adpressed drop-like pointed scales

- Eyes placed tangentially or close to the lateral border of frons. Integument bare or with more or less dense vestiture of longer

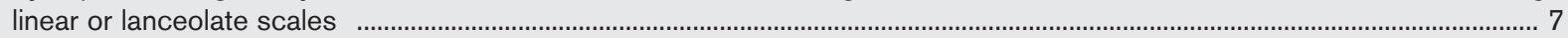

4 Elytra with big protuberances (outstanding at lateral margins) and whitish flattened sparse setae ...........................................5

- Elytra without protuberances in the firs half, with rows of very short setae ................................................................................

5 Elytral protuberances less developed; lanceolate setae decreasing in width apicad

Laparocerus (Fernandezius) subnodosus subcalvus (Wollaston, 1864)

- Elytral protuberances more developed and protruding; straight setae increasing in width apicad

.. Laparocerus (Fernandezius) sculptipennis (Wollaston, 1864)

6 Lateral dorsal margins of rostrum briefly notched behind the level of insertion of antennae; pregenae not swallen ventrally ....

Laparocerus (Fernandezius) tesserula seriesetosus (Wollaston, 1864)

- Lateral dorsal margins of rostrum normal, at least little narrowed behind the level of insertion of antennae; pregenae ventrally swallen

Laparocerus (Mateuius) auctus auctus (Wollaston, 1864)

7 Elytra with long straight setae or hairs over its entire surface or at least a few in the apical third (as long or longer than first

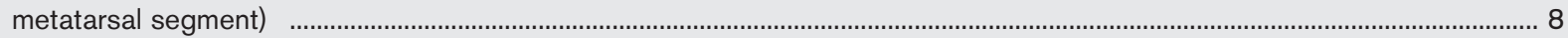

- Elytra devoid of long setae or hairs, bare or with very short curved or stout setae ................................................................. 12

8 A few long setae or hairs only on he apical third of elytra ................................................................................................... 9

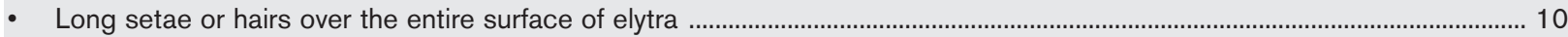

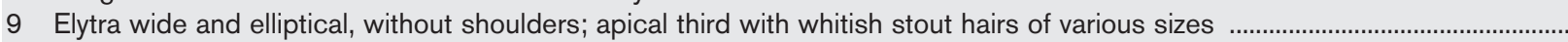

Elytra oblong, with shoulders; apical setae blackish, somewhat arcuate

Laparocerus ellipticus Wollaston, 1863

Laparocerus cephalotes n. sp.

10 Protibia with outer apical angle produced, somewhat expanded. Head and pronotum without of with recumbent inconspicuous pilosity

- Protibia with outer apical angle gently rounded. Head and pronotum with conspicuous protruding pilosity (shorter than on elytra)

11 Size $>6.5 \mathrm{~mm}$. Pronotum finely punctured. Elitral pilosity very thin, of clear colour, and disperse

Laparocerus sanchezi Roudier, 1957

Laparocerus lepidopterus lepidopterus Wollaston, 1864

- Size $<6.5 \mathrm{~mm}$. Pronotum coarsely punctured (females with a gibbosity at base). Elitral pilosity stout and black ......................................................................................... Laparocerus (Fortunotrox) puncticollis Wollaston, 1864

12 Elytral surface smooth, without protuberances (at most one at apex)

13

- Elytra with several striking protuberances along odd intervals Laparocerus mateui tuberosus n. sp.

13 Pronotum and elytra with vestiture of scales or minute setae. Protibia not expanded at apex 14

- Pronotum and elytra devoid of scales and setae. Apex of protibiae strongly expanded at both sides

Laparocerus (Machadotrox) aethiops aethiops Wollaston, 1864

14 Scutellum normal, triangular, visible. Elytral integument smooth, with more or less dense vestiture of lanceolate scales, building a design

- Scutellum minute, granular (seen from above), placed vertically on the thick basal border of the elytra. Elytral integument black with transversal rugosity and rows of minute recurved blackish setae .... Laparocerus (Amyntas) incomptus Wollaston, 1865

15 Size $<8 \mathrm{~mm}$. Pronotum with shiny or glossy integument; microsculpture superficial, with or without small punctures in addition to the larger ones

- Size $>8 \mathrm{~mm}$. Pronotum with alutaceous integument; reticulate microsculpture well impressed between the small and large punctures (precisely marked)

Laparocerus occidentalis Wollaston, 1864

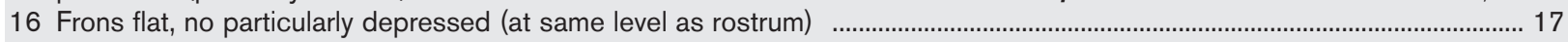

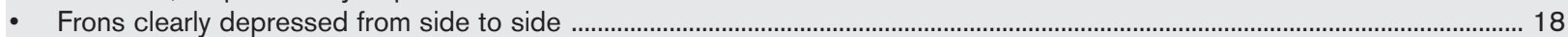

17 Head widest at level of eyes (eyes included). Elytra notably much broader than pronotum, with inconspicuous slanted arcuate setae of clear colour

Laparocerus bimbache n. sp.

- Head widest at level of neck. Elytra a little much broader than pronotum, with stout protruding blackish setae

ㅇ Laparocerus cephalotes n. sp.

18 Dorsum of rostrum subparallel, almost as broad as ventrally. Elytra apically rounded (in females with an apical tumefaction), with vestiture of very small arcuate setae

Laparocerus mendicus Wollaston, 1864

- Dorsum of rostrum abruptly constricted at front, almost half as wide as ventrally. Elytra acuminate at apex, with short inconspicuos apical pilosity

Laparocerus (Fortunotrox) orone hierroensis n. ssp. 
nidae, Entiminae). Journal of Natural History, 40(3537): 2001-2055. doi: 10.1080/00222930601046659

MachadO, A., 2007a. New species of Laparocerus Schoenherr, 1834 (Coleoptera, Curculionidae) from the island of Tenerife, Canary Islands. Zootaxa, 1457: 35-48.

MaCHADO, A., 2007b. New species of Laparocerus Schoenherr, 1834 from La Gomera, Canary Islands (Coleoptera, Curculionidae, Entiminae). Zootaxa, 1643: 1-38.

Machado, A., 2008a. Three new endogean species of Laparocerus Schoenherr, 1834 from the Canary Islands (Coleoptera, Curculionidae). Journal of Natural History, 42(17-18): 1277-1288. doi: 10.1080/ 00222930801942616

Machado, A., 2008b. New taxa of Laparocerus Schoenherr, 1832 from Madeira and Porto Santo, with a key to the species of the Madeiran Archipelago (Coleoptera, Curculionidae, Entiminae). Graellsia, 64(2): 307-328. doi: 10.3989/graellsia.2008.v64.i2.40

Machado, A., 2009. Nuevos Laparocerus Schoenherr, 1934 de La Palma, islas Canarias (Coleoptera, Curculionidae, Entiminae). Graellsia, 65(2): 183-224. doi: 10.3989/graellsia.2009.v65.i2.150

MACHADO, A., 2010. La morfología de Laparocerus undatus Wollaston, 1864 y consideraciones sobre la tribu Laparocerini Lacordaire, 1863 (Coleoptera, Curculionidae, Entiminae). Graellsia, 66(2): 233-280. doi: 10.3989/graellsia.2010.v66.025

Marseul, S, A. D., 1872-73. Monographie des Otiorhynchides d'apres les travaux de MM, les docteurs Seidlitz \& Stierlin, coordonnés par M. S.-A. de Marseul. L'Abeille, 11(Deuxième Série, Tome V): 449-557.
Roudier, A., 1957. Curculionides nouveaux ou peu connus des îles Canaries (Col.). Annales de la Société Entomologique de France, [1956], 125: 17-55.

Uyttenboogant, D. L., 1937. Contributions to the knowledge of the fauna of the Canary islands XIX. Tijdschrift voor Entomologie, 80: 75-118.

WinKLER, A. (ed.). 1924-1932. Catalogus Coleopterorum regionis palaearcticae. Albert Winkler, Wien. 1698 pp.

Wollaston, T. V., 1865. Coleoptera Atlantidum, being an enumeration of the Coleopterous insects of the Madeiras, Salvages and Canaries. Taylor \& Francis. London. $47+526$ pp. 